\title{
Investigation of European flexural and lateral torsional buckling interaction
}

\author{
Jönsson, Jeppe; Müller, Magnus Sundt; Gamst, Christian; Vales, Jan; Kala, Zdenek
}

Published in:

Journal of Constructional Steel Research

Link to article, DOI:

10.1016/j.jcsr.2019.01.026

Publication date:

2019

Document Version

Peer reviewed version

Link back to DTU Orbit

Citation (APA):

Jönsson, J., Müller, M. S., Gamst, C., Vales, J., \& Kala, Z. (2019). Investigation of European flexural and lateral torsional buckling interaction. Journal of Constructional Steel Research, 156, 105-121.

https://doi.org/10.1016/j.jcsr.2019.01.026

\section{General rights}

Copyright and moral rights for the publications made accessible in the public portal are retained by the authors and/or other copyright owners and it is a condition of accessing publications that users recognise and abide by the legal requirements associated with these rights.

- Users may download and print one copy of any publication from the public portal for the purpose of private study or research.

- You may not further distribute the material or use it for any profit-making activity or commercial gain

- You may freely distribute the URL identifying the publication in the public portal

If you believe that this document breaches copyright please contact us providing details, and we will remove access to the work immediately and investigate your claim 


\title{
Investigation of European flexural and lateral torsional buckling interaction
}

\author{
Jeppe Jönsson, Magnus Sundt Müller, Christian Gamst, Jan Valeš*, Zdeněk Kala* \\ Technical University of Denmark, DTU Civil Engineering, Brovej Building 118, DK-2800 Kgs. Lyngby \\ * BRNO University of Technology, Antonínská 548/1, 60190 Brno, Czech Republic
}

\begin{abstract}
The accuracy of the interaction methods for combined flexural and lateral torsional buckling are investigated using statistical data, which has become available after the introduction of Eurocode EN1993-1-1:2005. The freely available statistical data for geometric and material parameters for standard profiles are quite limited and as background documents are based on IPE 160 profile, our investigations are also based on this profile. A semi-probabilistic first order reliability approach is used and the resistance of the member is treated as a stochastic variable. Latin Hypercube Sampling is used for population sampling. This simulation approach for determination of the buckling interaction surface has not previously been reported. The Eurocode handles buckling interaction through two interaction equations. These equations include a number of interaction factors. The calculation of the interaction factors may be performed by one of two methods, referred to as Method 1 and Method 2. Both interaction methods make use of the buckling curves for determination of reduction factors for both flexural and lateral torsional buckling. The flexural buckling curve is well calibrated; however, this is not the case for lateral torsional buckling. It turns out that the methods may lead to unsafe designs when a lateral torsionally slender column is loaded predominantly in bending. The present paper investigates how the Eurocode emulate the complex behavior also for very slender beam-columns. The $0.1 \%$ quantile interaction curves are compared to those resulting from the use of Method 1 and Method 2.
\end{abstract}

Keywords: Flexural buckling, Lateral torsional buckling, Buckling interaction, Eurocode, Stability, FORM.

\section{Introduction}

When steel members are subjected to both axial compression and strong axis bending the structural response is highly complex and depends on many factors such as for example initial geometric imperfections, which can vary in both amplitude and shape, residual stress, plasticity and second order effects. This in turn as a consequence makes the modelling of such behaviour a difficult task, which has been under scrutiny ever since the work with the Eurocodes started over 40 years ago. A comprehensive historical review of the development of the European column buckling curves and finite element modelling can be found in Jönsson \& Stan [1] and the theoretical research on stability of beam-columns with combined compression and bending has thoroughly been described in the ECCS background document [2]. As described in the background document the current Eurocode EN 1993-1-1, [3], handles the interaction between axial compression and bending moment through two separate interaction formulae including interaction factors which can be calculated using either Method 1 or Method 2. These methods were developed over a period of nine years by two separate research teams from different universities in Austria, Germany, France and Belgium. The methods share the same theoretical background as outlined by Snijder [4], but employ different philosophies in their derivation of the coefficients leading to

Email address: jej@byg.dtu.dk (Jeppe Jönsson) the interaction factors. Method 1 aims for transparency by having effects represented by individual factors, while Method 2 aims at being simple and user friendly with compact interaction factors. The Eurocode EN 1990 [5] provides the basis of structural design and contains specific guidelines for the level of reliability of structures. The resistance of structures is traditionally found by deterministic methods using safety factors and conservative estimators of the variables that influence the load carrying capacity, however the reliability of structures is usually expressed in probabilistic terms, see [5] and [6]. The Eurocode provides the necessary guidelines for determining the reliability using a semi-probabilistic or even a fully probabilistic approach. The European test series and Monte Carlo simulations were performed on IPE160 sections, see for example Strating \& Vos [7]. Therefore, in the present investigation an IPE 160 beam-column is subjected to a reliability analysis according to the Eurocode [5]. The reliability analysis is performed using a First Order Reliability Method (FORM) with a semi-probabilistic approach where the resistance of the beamcolumn is treated as a stochastic variable, which has a Gaussian probability distribution. The resistance found in the analysis as the $0.1 \%$ quantile is then compared to the Eurocode interaction formulae calculated using both Method 1 and Method 2. This is done in order to determine whether or not the formulae, and their respective coefficients, meet the required level of reliability. The reliability analysis will be carried out by using Geometrically and Materially Nonlinear Imperfect Analyses (GMNIA) in the Finite Element (FE) software Abaqus [8]. 
A condensed introduction is given to the basic beam-column interaction factors found in the Eurocode and to the probabilistic theory utilized in the reliability analysis. The FE-model is explained in detail in order to facilitate reproduction of the results that are presented. Then a short investigation into the shape of the initial geometrical imperfections is given using buckling mode shapes and its effect on the structural carrying capacity. This is done to ensure that the most conservative approach to the initial imperfect geometry of the steel member is chosen as the basis for the simulations used for the reliability analysis. Finally the procedure of the reliability analysis is explained along with the given statistical geometric and material data, before the results of the analysis are presented and compared to the analytically calculated values from the Eurocode.

Details and elaborate explanations of the theories and investigations reported in this paper can be found in the master thesis by Gamst \& Müller [9], supervised by Jönsson and visiting PhD-student Vales at DTU.

\section{Preliminary theory}

\subsection{Beam-column interaction factors}

The design equations for beam-column interaction in the Eurocode are written in a linear format, meaning that non-linear effects need to be accounted for through the interaction factors utilized in the equations. The design effects of loadings on beam-columns are given as the normal force $N_{E d}$, the moments about the strong and weak axes respectively $M_{y, E d}$ and $M_{z, E d}$ and the changes of strong and weak axis moments due to shift of the neutral axis $\Delta M_{y, E d}$ and $\Delta M_{z, E d}$. The design resistances are given as $N_{R d}$ for the normal force and $M_{y, R d}$ and $M_{z, R d}$ for the moments about the strong and weak axes respectively. Essentially the utilisation with respect to each section force load effect is given by the ratio of the section force load effects and its design resistance. However in case of flexural buckling (FB) the normal force resistance is reduced by the buckling reduction factors, $\chi_{y}$ or $\chi_{z}$ corresponding to strong or weak axis buckling depending on which case is considered. Furthermore in cases where lateral torsional buckling (LTB) is relevant the strong axis moment resistance is reduced by the LTB reduction factor $\chi_{L T}$. In order to take moment amplifications caused by second order effects from axial force, plasticity, imperfections and the shape of the moment diagram into account interaction factors $k_{y y}, k_{y z}, k_{z y}$, and $k_{z z}$ are introduced in the Eurocode. With the introduced parameters the two beam-column interaction equations which have to be fulfilled according to the Eurocode[3] are:

$$
\begin{aligned}
& \frac{N_{E d}}{\chi_{y} N_{R d}}+k_{y y} \frac{M_{y, E d}+\Delta M_{y, E d}}{\chi_{L T} M_{y, R d}}+k_{y z} \frac{M_{z, E d}+\Delta M_{z, E d}}{M_{z, R d}} \leq 1 \\
& \frac{N_{E d}}{\chi_{z} N_{R d}}+k_{z y} \frac{M_{y, E d}+\Delta M_{y, E d}}{\chi_{L T} M_{y, R d}}+k_{z z} \frac{M_{z, E d}+\Delta M_{z, E d}}{M_{z, R d}} \leq 1
\end{aligned}
$$

Due to the somewhat complex process of including all the above mentioned effects into the four factors, the beam-column interaction factors are quite complex and may be calculated by

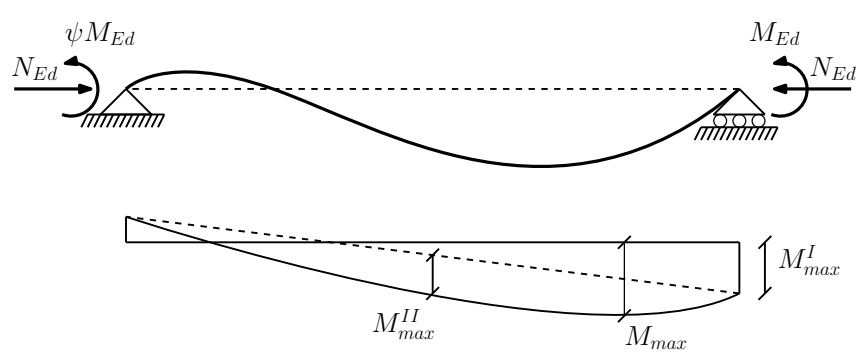

Figure 1: Location of the maximum bending moment when both first $\left(M^{I}\right)$ and second order bending moments $\left(M^{I I}\right)$ are present.

one of two independent methods referred to as Method 1 and Method 2 located in annex A and B of Eurocode 1993-1-1 [3]. Method 1 is developed by a French-Belgian research team and is characterized by its use of individual coefficients to describe each effect involved in beam-column interaction. This is also part of the continuity aspect of the method, where the equation reduces to a cross section check when effects are not present. Method 2 on the other hand is developed by a German-Austrian research team and is more compact as it is derived mostly from GMNIA testing, meaning it is more suitable for hand calculations. It is important to note that the two equations (1) and (2) are not related to a simple physical utilisation ratio, they are a result of equational manipulation of the classic stress utilisation ratio for the deformed situation. It is however clear from the ECCS background document [2] that both methods are based the same stress utilisation equation, which can be written in a classic format as:

$$
\frac{N_{E d}}{N_{R d}}+\frac{1}{1-\frac{N_{E d}}{N_{c r}}} \frac{N_{E d} u}{M_{R d}}+\frac{1}{1-\frac{N_{E d}}{N_{c r}}} \frac{C_{m} M_{E d, \max }^{I}}{M_{R d}}
$$

Where $u$ is the initial bow imperfection in the member, $M_{E d, \max }^{I}$ is the first order moment, and $C_{m}$ is the equivalent moment factor. The equivalent moment factor is implemented in order to avoid having to locate the maximum bending moment along the member length, caused by the addition of an axial force to a member already loaded in bending. This problem is illustrated in Figure 1. This is solved in Method 1 by assuming a sinusoidal shape of the first order moment, and in Method 2 by assuming a constant value of the first order moment. Both approaches will ensure a maximum total bending moment at midspan of the beam-column. This concludes the brief introduction to the stability equations related to Method 1 and Method 2.

\subsection{Structural reliability}

A first order reliability method with a semi-probabilistic approach is used in this paper to perform a reliability analysis on an IPE 160 beam loaded in axial compression and bending.

There are two methods of conducting a probabilistic reliability analysis; fully probabilistic or semi-probabilistic. A fully probabilistic approach entails modeling both the load and the resistance as stochastic variables before performing a Monte Carlo simulation in order to determine the failure surface, i.e. 


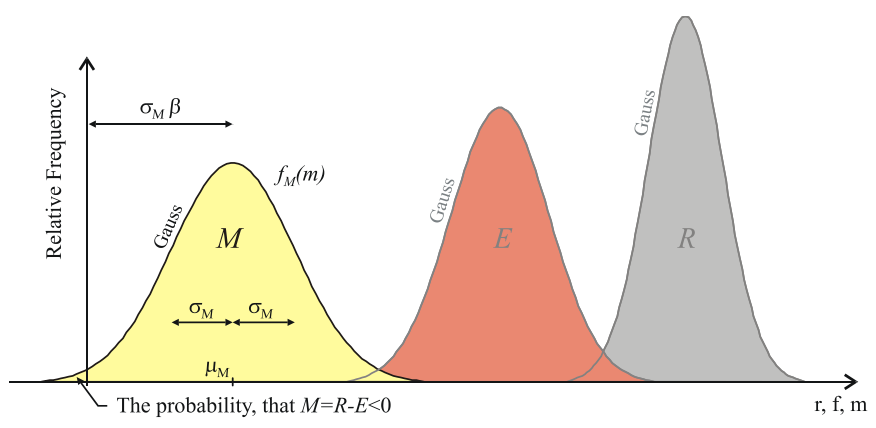

Figure 2: Design reliability condition.

the intersection between the two probability distributions. In a semi-probabilistic approach only the distribution of the resistance is known and the probability of failure can be estimated using the First Order Reliability Method (FORM), which will be elaborated on the following

Design conditions of reliability of standard EN 1990 are based on the FORM method, which was first introduced in the 1960s. It has now evolved to become one of the most important methods for evaluating structural reliability see Faber [10] and Zhao and Ono [11] especially in combination with the finite element method.

Structural reliability is expressed as a function of the random resistance $R$ and random load effect $E$ :

$$
M=R-E \geq 0
$$

where $M$ is the so-called safety margin. Probability of failure can be expressed by the equation

$$
P_{f}=P(R<E)=P(R-E<0)=P(M<0)
$$

Let us assume that $R, E$ are statistically independent variables with Gauss pdf with mean values $\mu_{R}, \mu_{E}$ and standard deviations $\sigma_{R}, \sigma_{E}$. Under these assumptions, $M$ also has Gauss probability density function (pdf) with mean value $\mu_{M}$ and standard deviation $\sigma_{M}$, which can be expressed as:

$$
\begin{aligned}
\mu_{M} & =\mu_{R}-\mu_{E} \\
\sigma_{M} & =\sqrt{\sigma_{R}^{2}+\sigma_{E}^{2}}
\end{aligned}
$$

The probability that $M=R-E<0$ is expressed by the integration of the pdf $f_{M}$ of random variable $M$ :

$$
P_{f}=\int_{\infty}^{0} f_{M} d m=\Phi\left(\frac{0-\mu_{M}}{\sigma_{M}}\right)=\Phi(-\beta)
$$

where $\Phi($ ) is the cumulative normalized Gauss distribution and $\mu_{M} / \sigma_{M}$ is the so-called reliability index $\beta$, see Figure 2. For a target value of the reliability index, for example $\beta=\beta_{d}=3.8$, the probability of failure is determined as $P_{f}=\Phi(-3.8)=7.2$. $10^{-5}$. In standard EN 1990,[5], reliability is generally verified by the inequality

$$
\beta=\frac{\mu_{M}}{\sigma_{M}} \geq \beta_{d}
$$

which upon substituting into (8) represents the probabilistic design condition $P_{f}<P_{f} d$, where $P_{f} d$ is the target value of

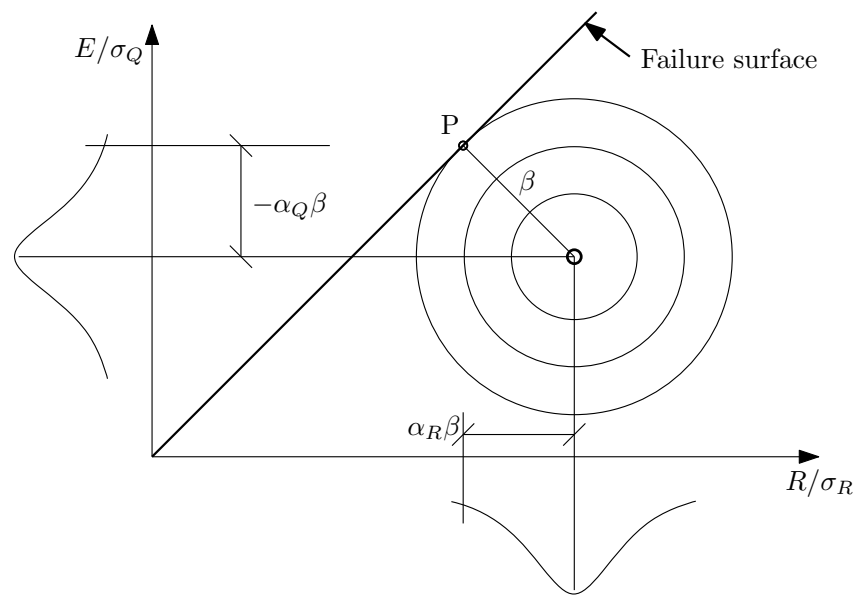

Figure 3: Design point $p$ and reliability index $\beta$.

failure probability [5]. For practical use, inequality (9) can be transformed by introducing the so-called FORM sensitivity factors $\alpha_{R}, \alpha_{E}$, which are obtained from the treatment of (7) as:

$$
\begin{aligned}
\sigma_{M} & =\sqrt{\sigma_{R}^{2}+\sigma_{E}^{2}}=\frac{\sigma_{R}^{2}+\sigma_{E}^{2}}{\sqrt{\sigma_{R}^{2}+\sigma_{E}^{2}}} \\
& =\frac{\sigma_{R}}{\sqrt{\sigma_{R}^{2}+\sigma_{E}^{2}}} \sigma_{R}+\frac{\sigma_{E}}{\sqrt{\sigma_{R}^{2}+\sigma_{E}^{2}}} \sigma_{E} \\
& =\alpha_{R} \sigma_{R}+\alpha_{E} \sigma_{E}
\end{aligned}
$$

The standard [5] permits the introduction of $\alpha_{R}, \alpha_{E}$ with constant values $\alpha_{R}=0.8, \alpha_{E}=0.7$, which for commonly occurring values $\sigma_{R}$ and $\sigma_{E}$ (common design conditions) lead to an approximately constant value $\sigma_{M} \approx 0.8 \sigma_{R}+0.7 \sigma_{E}$. Substitution of (6) and (10) into (9) leads to the design condition of reliability with formally separated sides expressing the design load and the design resistance:

$$
\mu_{E}+\alpha_{E} \beta_{d} \sigma_{E} \leq \mu_{R}+\alpha_{R} \beta_{d} \sigma_{R}
$$

The design value of the resistance $R_{d}$ is expressed as

$$
R_{d}=\mu_{R}-0.8 \beta_{d} \sigma_{R}
$$

The design load effect can be determined in the same manner by introducing $\mu_{E}, \sigma_{E}$ and $\alpha_{E}=0.7$. The principle is illustrated in Figure 3, which has been reproduced from standard EN 1990. The probability that the resistance is lower than the design value is then expressed as

$$
P\left(R \leq R_{d}\right)=\Phi\left(\frac{\mu_{R}-\alpha_{R} \beta_{d} \sigma_{R}-\mu_{R}}{\sigma_{R}}\right)=\Phi\left(-\alpha_{R} \beta_{d}\right)
$$

As in this paper, when the reliability index is taken as $\beta=\beta_{d}=$ 3.8 and the FORM sensitivity factor for resistance as $\alpha_{R}=0.8$ then the probability of having a resistance that is lower than the design resistance found by equation (12) as $\Phi(-0.8 \cdot 3.8)=$ $0.118 \%$, which approximately corresponds to the $0.1 \%$ quantile of the resistance pdf. The quantile resistance curves shown in this paper are thus found using equation (12), see Figure 4. The specific choice of these parameters will be discussed in a later section. 


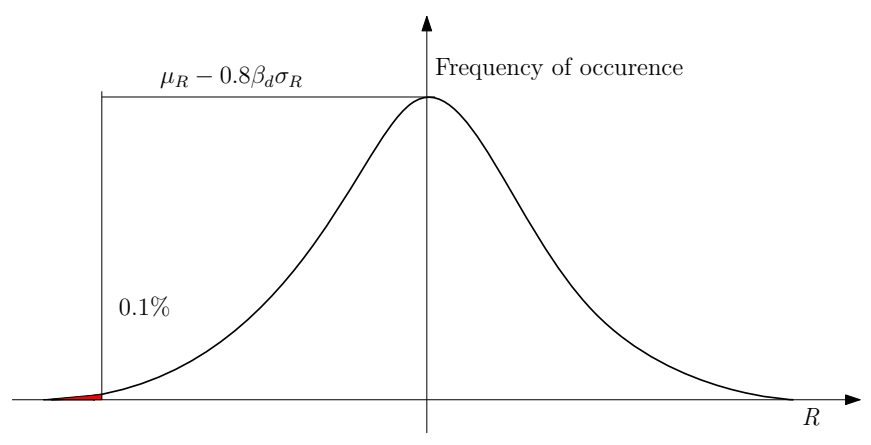

Figure 4: Illustration of the normal distributed resistance and the $0.1 \%$ quantile.

\section{Finite element modelling}

For this paper multiple GMNIA analyses have been executed using a finite element model in the software Abaqus, [8]. The presence of naturally occurring imperfections in the beamcolumn and in the material itself is approximately included in the model. The finite element model of the IPE 160 beamcolumn is made using rectangular shell elements referred to in the Abaqus as the S4 type element. Shell elements are used as they appropriately model the desired behaviour of structures in which one of the dimensions is significantly smaller than the other. The S4 element is a general purpose quadrangular 4node shell element without reduced integration, which is not sensitive to distortion and provides accurate solutions to buckling problems. The element density is chosen to be 16 elements along the flange width, and 16 elements along the web height as illustrated in Figure 5. This correlates with the recommendation from DNV [13] of using 3-6 elements per expected half wave. To avoid element deformation deficiencies along the member length from non-ideal ratios between element width and length, the number of elements in the longitudinal direction varies from 100 for the first few slenderness values, to 140 between $\lambda_{L T}=0.4$ and $\lambda_{L T}=1.4$, and finally 180 elements for the final range up to $\lambda_{L T}=2.1$.

In the Abaqus model the global $x$-axis is parallel to the longitudinal direction of the beam-column, the $y$-axis is parallel to
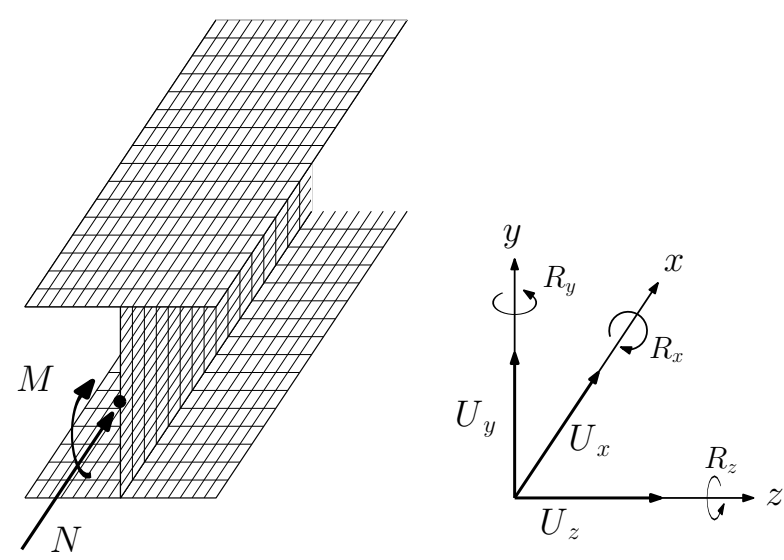

Figure 5: FE mesh, coordinate directions and nodal degrees of freedom.

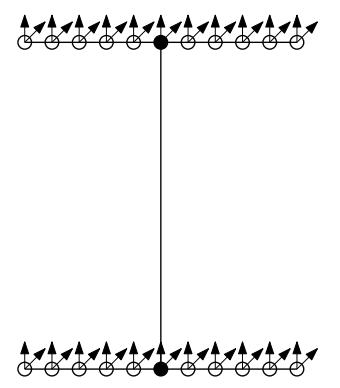

Flange node constraints

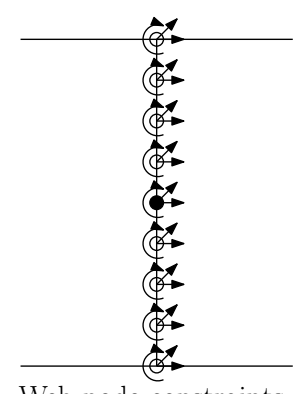

Web node constraints
Master nodes:

Slave nodes:

Figure 6: Constrained degrees of freedom in web and flanges.

the height of the web, and the $z$-axis is parallel to the flange width. Both external loads and boundary conditions are applied to the member ends utilising the kinematic constraints. These constraints allow for the degrees of freedom (DOF) of coupled nodes to be restricted to the movement of a master node. The beam-column boundary conditions correspond to the so called fork end-conditions and they are modelled using two multi point kinematic constraints at each end. The orientation of the nodal displacements and rotations are shown in Figure 5. The kinematically constraints are illustrated in Figure 6. It can be seen that in the end cross sections the nodal displacements $U_{x}$ and $U_{y}$ along the flange widths are constrained to displace as the central flange node. Furthermore the nodal displacements $U_{x}, U_{z}$ and $R_{x}$ are constrained along the web height to displace as the central web node (master node). This enables the application of the global boundary conditions at the central master web node and to apply the external force and moment load at this same master node. The boundary conditions applied to the two master web nodes ensures that the member is free to compress along its length whilst at the same time preventing the in-plane, lateral, and rotational movement at the member ends (but allowing transverse expansion of the web and flange). To constrain the model from moving as a stiff body in the axial $x$-direction a simple constraint $U_{x}$ is placed at mid-span of the beam-column. As stated the use of kinematic coupling constraints allows external forces to be applied at a single point at the beam-column ends, and furthermore it is worth noting that thereby one avoids having to use specific linear, non-linear or rigid plastic stress distributions as loads on the end cross sections. The model is loaded simultaneously with both axial force and bending moment at the central master web node at the member ends using a proportional loading scheme.

The model of the IPE160 cross section profile is not modelled to include the fillets usually present in such hot rolled profiles. This is done in order to reduce the complexity of the model. When I-profiles are modelled using shell elements the thickness of the elements leads to an overlap of material in the connection points between the flanges and the web, illustrated in Figure 7. This overlap is present in the finite element model and it is included in the analytical calculations according to Eurocode.

The $0.1 \%$ quantile results from the GMNIA analyses are to 


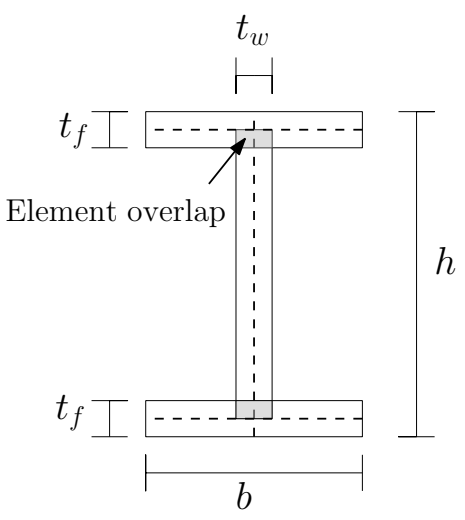

\begin{tabular}{rrr}
\multicolumn{3}{c}{ IPE160 } \\
\hline$h$ & 160 & $\mathrm{~mm}$ \\
$b$ & 82 & $\mathrm{~mm}$ \\
$t_{f}$ & 7.4 & $\mathrm{~mm}$ \\
$t_{w}$ & 5 & $\mathrm{~mm}$ \\
\hline
\end{tabular}

Figure 7: Nominal cross-section dimensions.

\begin{tabular}{ccc}
\multicolumn{4}{c}{ IPE160 Properties } \\
\hline$E$ & 210 & {$[\mathrm{GPa}]$} \\
$f_{y}$ & 235 & {$[\mathrm{MPa}]$} \\
$A$ & 1.98 & {$\left[10^{3} \mathrm{~mm}^{2}\right]$} \\
$W_{y, e l}$ & 107 & {$\left[10^{3} \mathrm{~mm}^{2}\right]$} \\
$W_{y, p l}$ & 121.7 & {$\left[10^{3} \mathrm{~mm}^{2}\right]$} \\
$I_{y}$ & 8.55 & {$\left[10^{6} \mathrm{~mm}^{4}\right]$} \\
$I_{z}$ & 681.7 & {$\left[10^{3} \mathrm{~mm}^{4}\right]$} \\
$K$ & 28.82 & {$\left[10^{3} \mathrm{~mm}^{4}\right]$} \\
$I_{\omega}$ & 4352 & {$\left[10^{6} \mathrm{~mm}^{6}\right]$} \\
\hline
\end{tabular}

Table 1: Nominal cross-section properties of the IPE160 profile model.

be compared to the carrying capacity (resistance) found using the Eurocode formulae calculated using the nominal values of the cross-section and material parameters. These are calculated including the added area from the overlap of the shell elements, and can be seen in Table 1 .

In the nonlinear finite element analysis the carrying capacity, i.e. the resistance, is determined as the maximum peak load obtained in the analysis as recommended in Eurocode 3 part 1-5 [14] for structures susceptible to buckling.

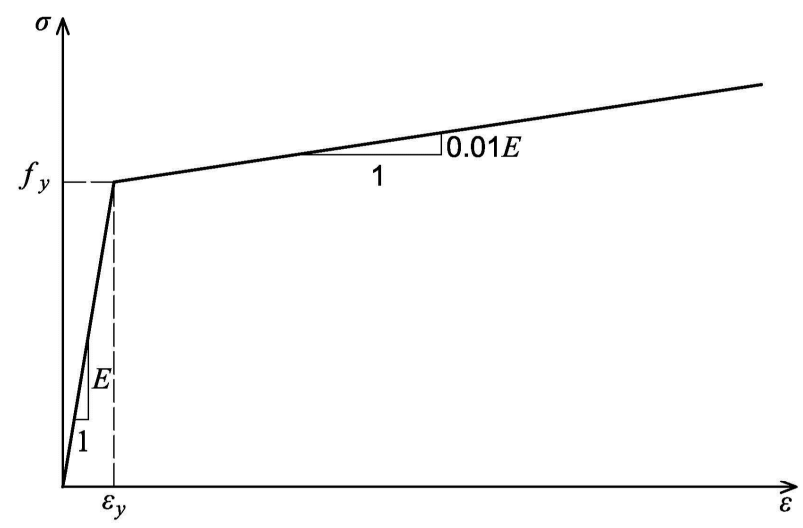

Figure 8: Bi-linear stress-strain curve used in the material model.

\subsection{Material model}

Detailed material properties such as statistically determined stress-strain curves for the steel behaviour are not a part of the data-set utilized in the presented reliability analysis. However a material model has to be implemented in the finite element model in order to adequately simulate the material behaviour. This is done by choosing an approximate simplified material stress-strain curve that models the expected behavior sufficiently. The plastic hardening properties of the material may add to the ultimate capacity past the elastic and first yield limit. In Eurocode 3 part 1-5 [14] four different assumptions for the material behaviour are proposed.

a) Elastic-plastic without strain hardening

b) Elastic-plastic with a nominal plateau slope of $E / 1000$

c) Elastic-plastic with a linear strain hardening slope of $E / 100$

d) True stress-strain curve modified from test results

Of the aforementioned options for the material stress-strain behaviour option (d) from the Eurocode is not feasible due to lack of test data. Buckling is largely an elastic phenomenon, meaning it is more critical at higher slenderness values, and the hardening behaviour is relevant at lower slenderness values. Thus, the plastic properties of the materials could be of importance to the ultimate capacity when performing non-linear buckling analyses. The case (c) with a hardening slope of $E / 100$ is chosen for the analyses carried out in this paper. A Von Mises plasticity model with isotropic hardening is used. The uniaxial behaviour of the material model is shown in figure 8 . The material yield stress in this paper is chosen to correspond to the nominal value of $235 \mathrm{MPa}$ used in the $S 235$ type steel. The slope of the stress-strain ratio from zero to the value of the material yield stress, represented by the Young's modulus $E$, is chosen to correspond to the nominal value of $210 \mathrm{GPa}$. Both The Youngs modulus $E$ and the yield stress $f_{y}$ are sampled with respect to the assumed probability density distributions.

\subsection{Geometric imperfections}

Geometric imperfections refers to the initial out-ofstraightness of the member and is sub-divided into two distinct types; global and local imperfections. Local imperfections mean imperfections which are related to the individual plate parts of the profile, such as initial deformations of the flange or the web. Analogously, global imperfections are imperfections related to the member as a whole such as initial deflections of the entire member. This paper considers the IPE160 profile, which is in cross section class 1 for pure compression and bending. This means that plastic stresses and an elastic plastic stress distribution may develop in both the flanges and the web without local buckling. Thus local imperfections are neglected in the simulations, see [15], under the assumption that their influence is negligible. Therefor in the present text the term geometrical imperfections only refers to the global imperfections. The Eurocode allows that the geometric imperfections of a member 


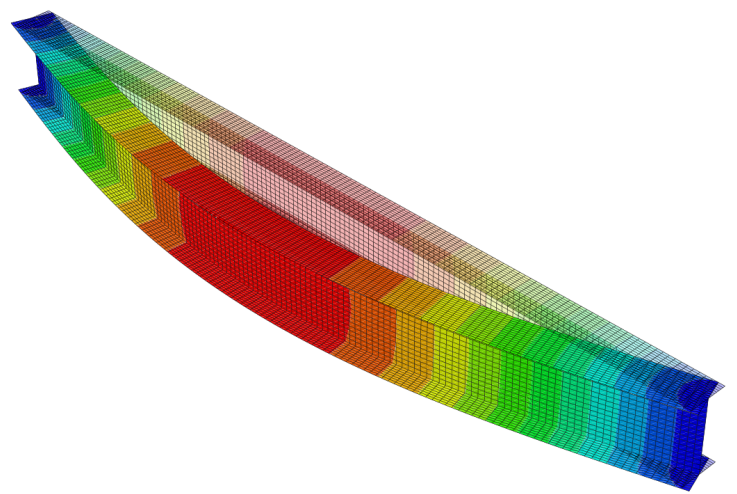

Figure 9: Buckling mode for weak axis flexural buckling (FBz).

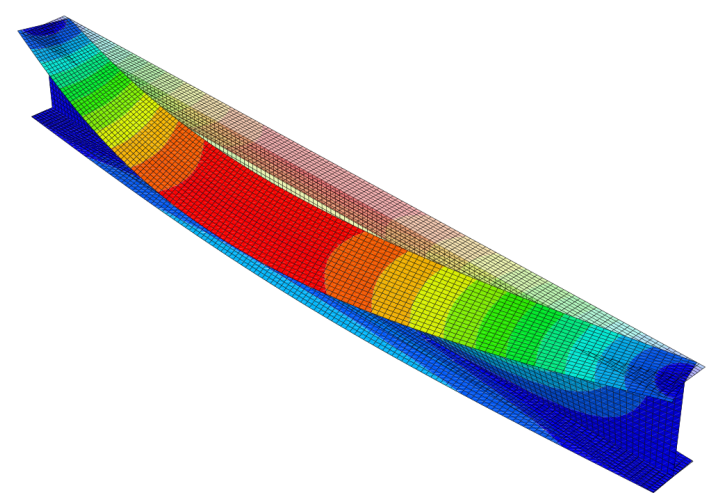

Figure 10: Buckling mode for lateral torsional buckling (LTB).

analysed with FE-tools can be based on the shape of the critical buckling modes [14]. Examples of geometric imperfection shapes based on the buckling modes can be seen in figures 9 and 10. These examples are taken from one analysis performed in this paper. As the scale of this deformation is normalized and an imperfection scale factor is introduced to give the member appropriate amplitude of the out-of-straightness. The nominal value of the scale factor of the imperfections in advanced finite element analysis is usually set to $L / 1000$, as residual stresses are modelled separately in the model. From EN1090-2 [16] the maximum allowed out-of-straightness, or amplitude of the bow imperfection, is given as $L / 750$. This implies that the value of $L / 1000$ corresponds to $75 \%$ of the maximum allowed geometric imperfection, which is a value that existing literature generally agrees is a fitting approximation [15], [17]. The imperfection and statistical modeling used in the simulations of this paper are described later in section 4 . The recommended values of the geometrical imperfection in table 5.1 in EC1993-1-1 [14] yields a much larger amplitude of the initial imperfection. This is because these values are meant to model the combined effect of both out-of-straightness and residual stress, and thus the use of these would be incorrect in this model where these effects are separated. Furthermore these values are too conservative as discussed in [1].

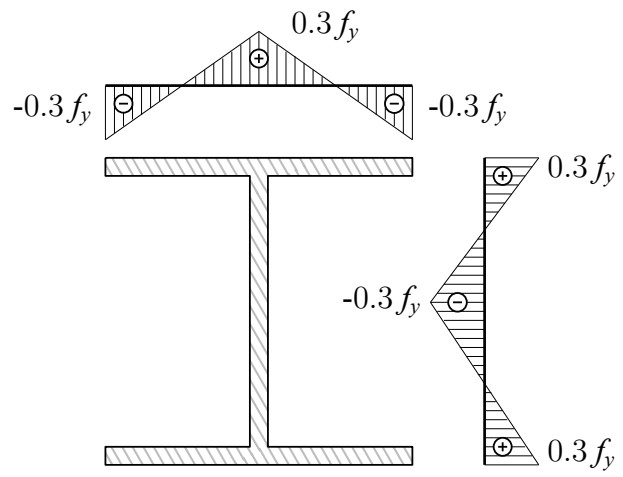

Figure 11: Linear residual stress distribution $\sigma_{r}$ assumed in IPE160 profiles.

\subsection{Residual stress}

The manufacturing process of steel beams leaves material imperfections in the form of residual stress in the profiles which in turn affects the buckling capacity [2]. This residual stress is assumed to be uniform along the member and varies across the flanges and web. The height to width ratio and the thicknesses of the flanges and web has an influence on the residual stress distribution. The residual stress distribution is considerably affected by how the cross section is made, that being welded or rolled, and there are many proposals as to how this should be modelled in an FE-analysis throughout existing literature, e.g. [15], [18], [19], see also the discussion in [1]. A typical approximate linear shape of the residual stress distribution for a hot-rolled profile can be seen in figure 11, and it is this shape which is utilized in the analyses carried out in this paper. The ratio between height and width $h / b$ determines the amplitude of the residual stress. A value of $h / b<1.2$ gives an amplitude of $0.5 \cdot f_{y}$, while more 'slender' cross sections at $h / b>1.2$ have an amplitude of $0.3 \cdot f_{y}$ as described in [18]. The IPE 160 profile investigated in this paper falls under the latter case, and thus the nominal value of the amplitude of the residual stress is set to $0.3 f_{y}$. The Eurocode states that the residual stresses may be represented by a stress pattern from the fabrication process with amplitudes equivalent to the expected values [14].

In this paper the residual stress distribution, $\sigma_{r}$, is implemented in the FE- model using an equivalent temperate load. The procedure consists of giving the model a temperature load in an initial step. The relation between the material stress, here $\sigma_{r}$, caused by temperature induced strain gives

$$
\sigma_{r}=E \alpha \Delta T \quad \Rightarrow \quad \Delta T=\frac{\sigma_{r}}{E \alpha_{s}}
$$

Where $E$ is the material Young's modulus, $\Delta T$ is the temperature increment, and $\alpha_{s}$ is the thermal expansion coefficient. By solving for the temperature increment, a temperature load $\Delta T$ can be applied to the model. It should be noted that the software and finite element calculation is based on the use of interpolation points at which stresses are found. For the chosen element the membrane stresses are approximately constant within each element, but the software may average these between elements. This means that the correctly obtained residual stresses 


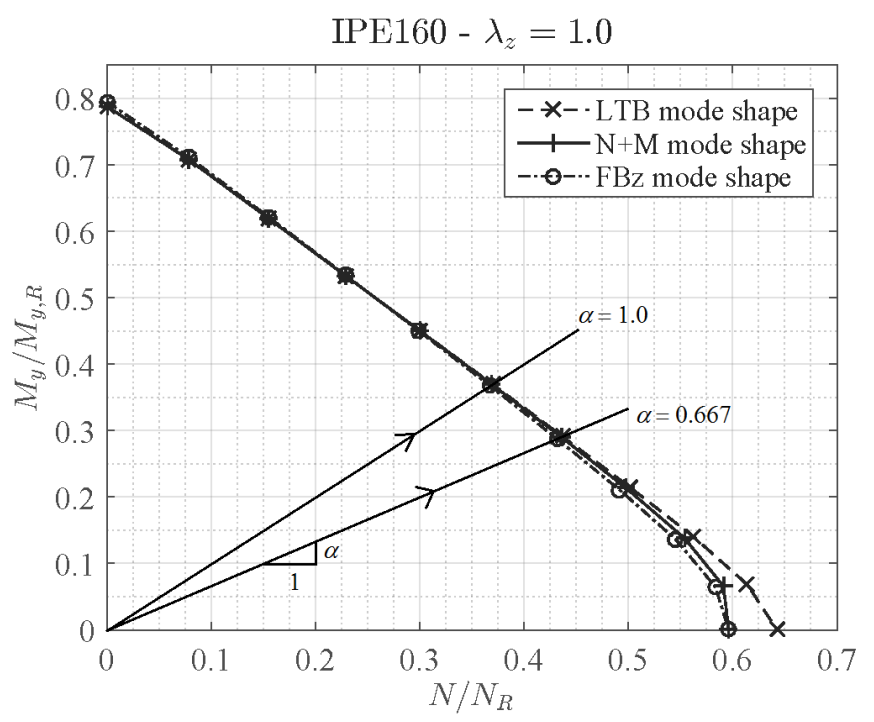

Figure 12: N-M-diagram for an IPE 160 profile where three different mode shapes: LTB, FB, and interactional between the two, are used to model the imperfections in the simulation.

obtained in the model are only precise at the interpolation points and not necessarily at the edges.

\subsection{Imperfection shapes and proportional loading}

In nonlinear finite element analyses the buckling mode shape from an initial linear buckling analysis is most often used as a basis for the assumed geometrical imperfections in a beamcolumn. Figure 12 shows the results of GMNIA analysis with different choices of imperfection mode shapes for proportional loading paths with combined moment and normal force. The load paths with inclinations of $\alpha=1.0$ and $\alpha=0.667$ have been included to illustrate the proportional loading paths. The GMNIA results shown in the Figure 12 corresponding to the maximum value of the load proportionality factor are found for a relative slenderness of $\lambda_{z}=1$ and otherwise identical parameters. The main difference is seen for high relative magnitudes of compression. In this area the upper results curve corresponds to the use of the LTB mode shape, the intermediate curve corresponds to the interactional mode shape found by buckling analysis (standard choice) and finally the lowest curve corresponds to the use of the weak axis FB mode as imperfection shape. It can be seen that the choice of global imperfection shape has an influence on the final capacity. In situations dominated by bending the pure LTB shape most often gives more conservative results and in situations dominated by compression use of the pure FB shape for buckling about the weak axis (FBz) often gives conservative results.

The main difference between the mode shapes is that the flexural buckling mode consists only of lateral deformation $u$, while the LTB mode also includes rotation $\phi$ of the cross-section. And since the buckling mode shape is normalized with respect to maximum displacement before it is multiplied by the imperfection factor, i.e. for example $L / 1000$, to get the imperfection shape, the ratio between the amount of lateral and rotational

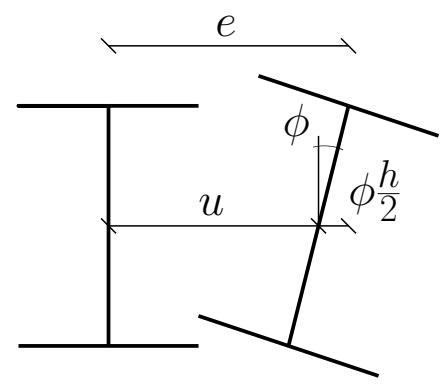

Figure 13: Lateral and rotational imperfection parameters in LTB.

deformation is the key to the difference in the final capacity. The maximum geometrical imperfection $e$ at the top of the web, when both rotational $\phi$ and lateral deformation $u$ are present, is shown in Figure 13 and can be written as

$$
e=u+\phi \frac{h}{2}
$$

when assuming small rotations.

As seen in Figure 12 the results for the conventionally "combined mode" imperfection shape follows the results for the LTB imperfection shape closely for load paths with "inclinations" greater than one, i.e. $\alpha \geq 1$. For load paths with "inclinations" lower than one, $\alpha<1$, the use of an imperfection mode corresponding to the weak axis buckling mode (FBz) seems to give the most conservative results. This suggests that the use of an interactional standard "combined" buckling mode shape may be non-conservative in the range of high axial force. In the presented implementations it has therefore been decided to use the LTB imperfection shape for high bending moments corresponding to $\alpha \geq 1$, and the FBz imperfection shape for high axial forces corresponding to $\alpha<1$, where the load proportionality ratio (inclination) is given by

$$
\alpha=\frac{M_{y} / M_{y, R}}{N / N_{R}}
$$

where the cross section plastic compression resistance and the strong axis moment resistance respectively are given by

$$
\begin{aligned}
N_{R} & =A f_{y} \\
M_{y, R} & =W_{y, p l} f_{y}
\end{aligned}
$$

As described the non-linear finite element simulations are performed using proportional load increments in which the ratio between normal force and moment load is kept constant. Since the problem is of a non-linear character non-proportional load paths will change the results due to a changed plastic energy dissipation. In the following GMNIA finite element results are presented for 11 load paths. Table 2 defines the different load paths used in the simulations and the imperfection shape used.

\subsection{Column lengths and slenderness ratios}

The length of the beam-columns investigated was chosen in order to represent lengths which could be used in a real world 


\begin{tabular}{ccccc} 
Path & $n=N / N_{R}$ & $m=M_{y} / M_{y, R}$ & $\alpha=m / n$ & Imp. \\
\hline 1 & 0.0 & 1.0 & $\infty$ & LTB \\
2 & 0.1 & 0.9 & 9.00 & LTB \\
3 & 0.2 & 0.8 & 4.00 & LTB \\
4 & 0.3 & 0.7 & 2.33 & LTB \\
5 & 0.4 & 0.6 & 1.50 & LTB \\
6 & 0.5 & 0.5 & 1.00 & LTB \\
7 & 0.6 & 0.4 & 0.667 & FBz \\
8 & 0.7 & 0.3 & 0.428 & FBz \\
9 & 0.8 & 0.2 & 0.250 & FBz \\
10 & 0.9 & 0.1 & 0.111 & FBz \\
11 & 1.0 & 0.0 & 0 & FBz \\
\hline
\end{tabular}

Table 2: Proportional compression and moment loading.

\begin{tabular}{ccccccc}
$\lambda_{L T}$ & $\lambda_{z}$ & $\sim L[\mathrm{~m}]$ & & $\lambda_{L T}$ & $\lambda_{z}$ & $\sim L[\mathrm{~m}]$ \\
\cline { 1 - 2 } \cline { 5 - 7 } 0.2 & 0.226 & 0.397 & & 1.2 & 1.907 & 3.358 \\
0.3 & 0.343 & 0.603 & & 1.3 & 2.175 & 3.829 \\
0.4 & 0.466 & 0.820 & & 1.4 & 2.466 & 4.342 \\
0.5 & 0.596 & 1.049 & & 1.5 & 2.782 & 4.897 \\
0.6 & 0.736 & 1.296 & & 1.6 & 3.122 & 5.496 \\
0.7 & 0.889 & 1.564 & & 1.7 & 3.487 & 6.139 \\
0.8 & 1.055 & 1.858 & & 1.8 & 3.877 & 6.825 \\
0.9 & 1.239 & 2.180 & & 1.9 & 4.291 & 7.554 \\
1.0 & 1.440 & 2.530 & & 2.0 & 4.729 & 8.326 \\
1.1 & 1.663 & 2.927 & & 2.1 & 5.192 & 9.140 \\
\hline
\end{tabular}

Table 3: $\lambda_{L T}$ values and corresponding $\lambda_{z}$ and beam lengths, $L$.

scenario, where the $\lambda_{L T}$ values ranged from 0.2 to 2.1 , equivalent to lengths of around $0.397 \mathrm{~m}$ to $9.14 \mathrm{~m}$. The finite element simulations are performed using 20 different values of $\lambda_{L T}$.

Since results given in the following are related to these specific values of the LTB slenderness, $\lambda_{L T}$, and thereby enable comparison to Eurocode, the length of the member used in each finite element simulation is determined through the related critical LTB length of the member. The definition of the LTB relative slenderness gives us

$$
M_{c r}=\frac{M_{y, R}}{\lambda_{L T}^{2}}
$$

and the classic solution for the critical LTB moment for constant moment is given by:

$$
M_{c r}=\sqrt{\frac{\pi^{2} E I_{z}}{L^{2}}+\left(G K+\frac{\pi^{2} E I_{\omega}}{L^{2}}\right)}
$$

in which $I_{z}$ is the weak axis bending stiffness, $G$ is the shear modulus, $K$ the torsional stiffness and $I_{\omega}$ is the warping stiffness. Solving for the length $L$ in the classic equation (20) and introducing the critical moment expressed from equation (19) determines the length to use in the simulation as:

$$
L=\sqrt{\frac{\pi^{2} \lambda_{L T}^{4}}{2 M_{y, R}^{2}}\left(E I_{z} G K+\sqrt{\left(E I_{z} G K\right)^{2}+\frac{4 E I_{\omega} E I_{z} M_{y, R}^{2}}{\lambda_{L T}^{4}}}\right)}
$$

In the analysis performed beams are analysed with statistically varying cross-section geometry and material properties. Since results are normalized there will be small changes in the length of the beam-column as the slight differences in geometry and material properties affect the length. Having the length of the beam column and the specific geometry, then the related weak axis FB slenderness ratio $\lambda_{z}$ can be found. Table 3 gives the values of the 20 different LTB slenderness ratios, the FBz slenderness ratios and the nominal column lengths.

\section{Statistical parameters}

A reliability analysis carried out using GMNIA analyses requires statistical information about geometric and material properties of the investigated beam-column in order to reflect the naturally occurring variation such a beam-column would have in real life. Information on the statistical parameters, which are used in the population sampling for the IPE 160 profiles have been provided by Faculty of Civil Engineering, Brno University of Technology, and are taken from the same data base used in the paper by Melcher et al [20]. The data are more than ten years old and have been used even though there is a possibility that advancements in steel production over the past decade might have changed these data. However steel producers no longer disclose such data and newer information does not seem to be available. Relatively little recent statistical data on the metallurgical products is available, see for example [21] and [22].

In total there are eight randome input parameters which all are mutually statistically independent and are considered to have a Gaussian probability distribution. These parameters are listed in Table 4 along with their mean value and standard deviation. According to the results of the stochastic sensitivity analysis [23] the Poisson ratio was assumed to be constant $v=0.3$. All other cross section properties are governed by these geometrical and material parameters. Meaning that e.g., a dataset with a small cross section height and width would have a corresponding smaller area, moment of area, critical elastic moment, etc.

Except for the yield stress the mean values given in Table 4 correspond to the characteristic value. In the present simulations the yield stress $f_{y}$ is assumed to be a stochastic variable with a normal distribution with a characteristic value of

\begin{tabular}{lcccc} 
Parameter & & Mean & St. dev. & Unit \\
\hline Cross-section height & $h$ & 160 & 0.71 & {$[\mathrm{~mm}]$} \\
Cross-section width & $b$ & 82 & 0.81 & {$[\mathrm{~mm}]$} \\
Web thickness & $t_{w}$ & 5 & 0.2 & {$[\mathrm{~mm}]$} \\
Flange thickness & $t_{f}$ & 7.4 & 0.34 & {$[\mathrm{~mm}]$} \\
Youngs modulus & $E$ & 210 & 10 & {$[\mathrm{GPa}]$} \\
Yield stress & $f_{y}$ & 297.3 & 16.8 & {$[\mathrm{MPa}]$} \\
Residual stress & $\sigma_{r}$ & 89.19 & 17.83 & {$[\mathrm{MPa}]$} \\
Normalized imp. & $\bar{e}$ & 0 & 1 & \\
\hline
\end{tabular}

Table 4: Statistical geometric and material parameters for the IPE 160. 
$235 \mathrm{MPa}$ corresponding to the $5 \%$ fractile of the distribution [5]. It should be noted that a different probability distribution such as the log-normal distribution could alternatively have been chosen. The steel producers only have to guarantee that the yield stress meets this 5\% fractile requirement and as a result of this the mean yield stress of steel with a quality of $S 235$ will have a significantly higher value than $235 \mathrm{MPa}$. A consequence of this is that the yield stress of the steel used in this reliability analysis is quite a bit higher than $235 \mathrm{MPa}$ as they are sampled from a population with a mean value of $297.3 \mathrm{MPa}$ [20].

So far in this paper the magnitude of the global geometrical imperfection has been introduced as being $L / 1000$, a choice based on recommendations from [15] and practice used in developing the Eurocode buckling curves [17]. However, that would imply that all beams of the same length and thus the same slenderness would have the same imperfections, which of course does not reflect real beams adequately. The imperfection magnitude is therefore assumed to be a Normal distributed random variable with a mean value, $\mu_{e}$ and a standard deviation, $\sigma_{e}$. The model imperfection is thus given by

$$
e=\mu_{e}+\bar{e} \cdot \sigma_{e}
$$

in which $\bar{e}$ is assumed to be a normalized imperfection parameter which is normally distributed with a standard deviation of one. Note that the model imperfection $e$ contains both the lateral imperfection $u$ and the torsional imperfection $\phi$, for the LTB shape of global initial imperfections, and only $u$ in the FBz shape of imperfections. Given that the average beam is considered to be a perfectly straight beam which might have imperfections in both positive and negative directions, the mean of the imperfection is zero

$$
\mu_{e}=0
$$

It is then assumed that $95 \%$ of the realizations of the imperfection are within the tolerance limits of $\pm L / 1000$, i.e. that a $95 \%$ confidence interval is used to derive the standard deviation of the geometrical imperfections. Let

$$
P(X \leq x)=F^{-1}(x)
$$

where $F^{-1}(\mathrm{x})$ is the cumulative distribution function for the imperfection magnitude $x=e$. The confidence interval can be written as

$$
0.95=P\left(\mu_{e}-\frac{L}{1000} \leq e \leq \mu_{e}+\frac{L}{1000}\right)
$$

Then in order to use the inverse cumulative distribution function for the standard Normal distribution $\Phi$, the variable $\mathrm{x}$ which in this case corresponds to the limits of the confidence interval, has to be standardised. Thus

$$
P(X \leq x)=\Phi\left(\frac{x-\mu_{e}}{\sigma_{e}}\right)
$$

This facilitates solving for the standard deviation as follows

$$
\begin{aligned}
0.95 & =\Phi\left(\frac{\mu_{e}+\frac{L}{1000}-\mu_{e}}{\sigma_{e}}\right)-\Phi\left(\frac{\mu_{e}-\frac{L}{1000}-\mu_{e}}{\sigma_{e}}\right) \\
& =\Phi\left(\frac{L}{1000 \sigma_{e}}\right)-\Phi\left(-\frac{L}{1000 \sigma_{e}}\right) \\
& =2 \cdot \Phi\left(\frac{L}{1000 \sigma_{e}}\right)-1 \\
\Rightarrow \quad & 0.975=\Phi\left(\frac{L}{1000 \sigma_{e}}\right) \\
\Rightarrow \quad & \sigma_{e}=\frac{L}{1960}
\end{aligned}
$$

By substituting equations (23) and (27) into equation (22) the magnitude to be used in the simulation becomes:

$$
e=\bar{e} \cdot \frac{L}{1960}
$$

In the sampled data the normalized imperfection parameter $\bar{e}$ is given and according to equation (28) it has to be multiplied by $L / 1960$ to be used in the finite element model. This approach is also the basis for the studies in [23] and [6]. The maximum sampled value in the present realization is $\bar{e}_{\text {max }}=2.22696$ which corresponds to about $e=L / 880$, which is a little smaller than the maximum allowed out-of-straightness of $L / 750$ in EN1090-2 [16]. If the number of samples are increased this value will probably increase.

The total 30 random realizations of the eight input variables of the IPE160 steel member are simulated. The Latin Hypercube Sampling (LHS) method is used, see Mckay et al [12]. Input random variables are introduced as statistically independent. 


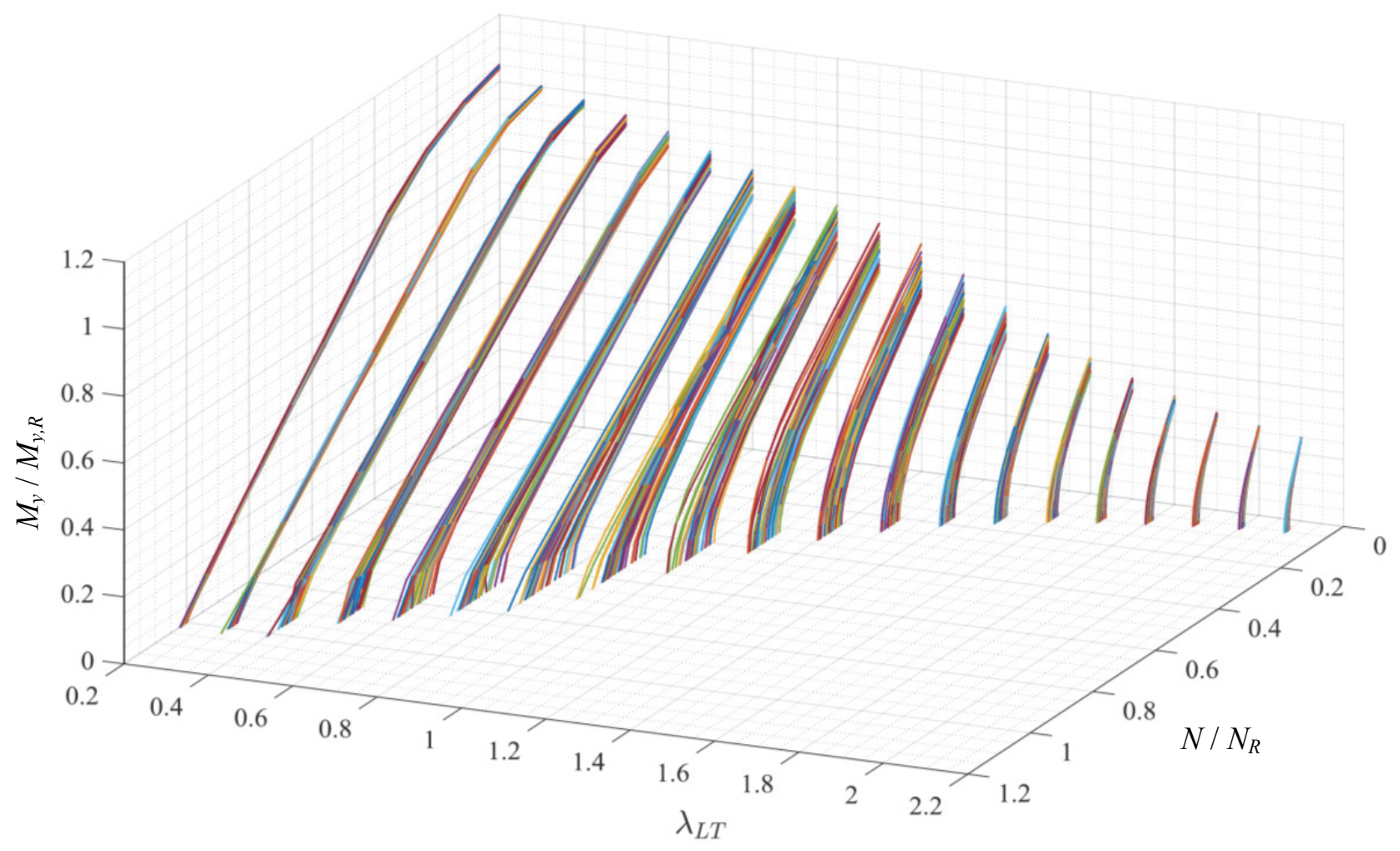

Figure 14: Three dimensional plot illustrating the results of the 6600 finite element simulations.

\section{Finite element simulations and statistic verification}

For each of the 20 different LTB relative slenderness ratios, $\lambda_{L T}$, given in Table 3, finite element simulations are performed with the 30 sampled IPE160 data sets for each of the 11 proportional load ratios between axial force and bending moment given in Table 2. All in all this corresponds to $20 \cdot 30 \cdot 11$ simulations, i.e. 6600 in total.

For each of these simulations the maximum value of the proportional load factor was extracted and used to find the maximum values of the combined axial force and bending moment loading in order to obtain the data pool used in the probabilistic treatment to find the $0.1 \%$ quantile. Figure 14 illustrates the resulting data pool as the axial force and bending moment interaction space of the problem for each analyzed LTB slenderness, $\lambda_{L T}$, by connecting the results of the interaction curves in each of the 30 data sets. Some results of the 30 input sets are hidden by others, but the statistical variation is clear.

In order to show that the results are statistically valid it is verified that the results have a Gaussian distribution. This is done by taking all the data from each relative slenderness value in the simulations and test them using an Anderson-Darling test with unknown mean values and standard deviations. The AndersonDarling test is a "goodness-of-fit" test, see [25] and [26], which is used to check the hypothesis of a population sample having a certain probability distribution. The test did not reject the hypothesis of normal distribution of the results with a significance level of $1 \%$. To achieve this the maximum size of the increments in the finite element analysis had to be reduced to prevent result fluctuations in the simulations due to difficulties in following the correct buckling branch in cases with relatively small imperfections. Further more it is important to note that the Anderson-Darling test does not indicate that you definitely have the probability distribution you are testing for. It only indicates that it is unlikely that you do not have the distribution in question. Nevertheless it is concluded based on the Anderson-Darling test that the load-carrying capacity results from the beam-column simulations can be regarded as normal distributed.

\section{Reliability analysis}

According to the Eurocode reliability is defined as "the ability of a structure or a structural member to fulfil the specified requirements, including the design working life, for which it has been designed. Reliability is usually expressed in probabilistic terms" [5]. With regard to the ultimate limit state this can be interpreted as the ability of a member to resists the effects of actions exerted on the member. In this section the processing of the simulation data pool and the basis for comparison with the Eurocode will be briefly discussed before results are presented in the next section.

Annex B of Eurocode EN1990, [5], provides recommendations for a reliability index, $\beta$, in the ultimate limit state in conjunction with reliability classes and Clause B3.2(2) in EN1990 associates these reliability classes with consequence classes. To be brief Table $\mathrm{B} 2$ in this annex recommends a minimum value 


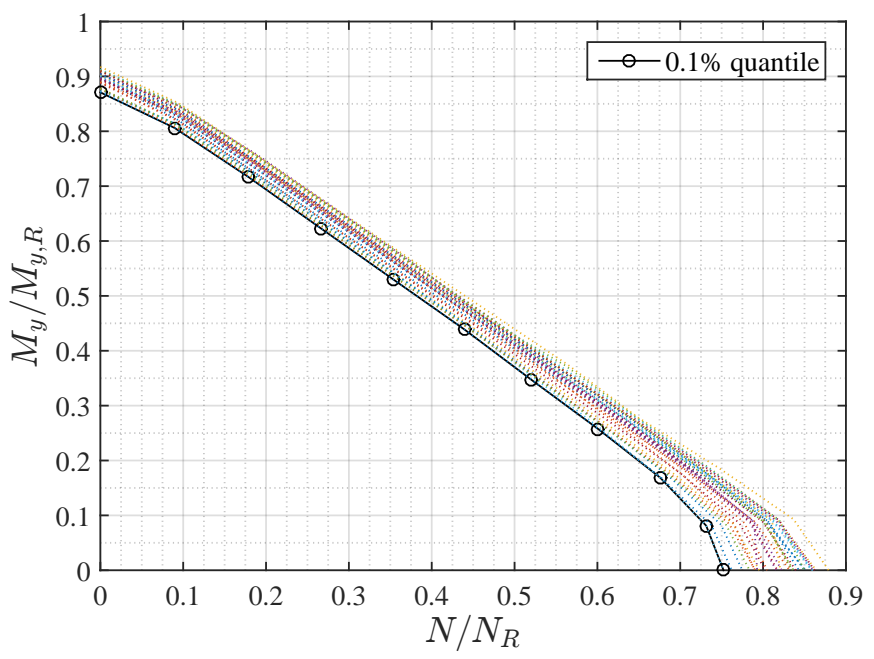

Figure 15: The interaction curves of the 30 input sets and the $0.1 \%$ quantile for $\lambda_{L T}=0.5$.

for $\beta$ with a 50 year reference period and reliability class 2 (corresponding to consequence class 2 ) of $\beta_{d}=3.8$. The FORM sensitivity factor for the resistance is given in Annex $\mathrm{C}$ of the EN1990 in clause C.7(3) as $\alpha_{R}=0.8$. Thus the probability of the resistance being lower than the design value can be written as

$$
\Phi\left(-\alpha_{R} \beta_{d}\right)=\Phi(-0.8 \cdot 3.8)=0.1183 \%
$$

This means that the probability of having a lower design value of the resistance is $0.1183 \%$. This approximately corresponds to the $0.1 \%$ quantile of the distribution of the resistance and therefore forms the basis for the comparison of the results from the reliability analysis with the calculated resistances from Method 1 and 2 in the Eurocode. Using the simulation data pool of resistance the mean value $\mu_{R}$ and the standard deviation $\sigma_{R}$ of the 30 results in each data set is used to find the $0.1 \%$ resistance quantile. The $0.1 \%$ resistance quantile is thus given dependent on the proportional load case and the LTB slenderness values by:

$$
R_{0.1 \%}\left(\alpha, \lambda_{L T}\right)=\mu_{R}-\alpha_{R} \beta_{d} \sigma_{R}=\mu_{R}-0.8 \cdot 3.8 \sigma_{R}
$$

The definition of the quantile is illustrated in Figure 4 and the $0.1 \%$ quantile of the 30 input sets for $\lambda_{L T}=0.5$ is illustrated in Figure 15.

\section{Results, comparison and discussion}

In this section the results from all the GMNIA simulations in the form of the $0.1 \%$ quantile resistance found through the reliability analysis will be compared to the corresponding analytically calculated resistance using the beam-column interaction formulae in the Eurocode with the interaction factors described by the two methods Method 1 and Method 2. In this regard and in the discussion the Eurocode resistance formulae are compared as being conservative or not or being on the safe or unsafe side in comparison to the $0.1 \%$ quantile results. This is done since the quantile results are based on the probabilistic approach of the code.

In the following the results related to pure flexural buckling and to pure lateral torsional buckling are shown and compared. The dependency of the simulation resistances on the imperfection is illustrated using trend lines and the correlation coefficient of each trend line. Then the interactional buckling results are illustrated and compared for combined bending and axial compression for all the values of the lateral torsional slenderness using both Method 1 and Method 2. Finally the $0.1 \%$ resistance results are used to find the $k_{y y}$ and $k_{z y}$ interaction factors (by replacing the $M_{y, 0.1 \%} / M_{y, R}$ values of the interaction curves) and compare to those of both Method 1 and Method 2 for a relevant span of $\lambda_{L T}$ slenderness values.

\subsection{Flexural buckling and lateral torsional buckling}

Due to the format of the beam-column interaction formulae the accuracy of the beam-column interaction capacities are heavily influenced by how well the pure instability cases of LTB and FB are estimated by the Eurocode. The FB curves are generally known to accurately describe the stability load of a column susceptible to flexural buckling, however the curves describing "rolled and equivalent welded" sections susceptible to lateral torsional buckling does not show the same level of accuracy, see [19] and [27]. In the case of pure axial compression this makes the analytical formulae a good basis for comparison with the results acquired from the GMNIA analyses, and this comparison could in some sense be used as a validation tool for the FE model. For pure bending the results are of interest due to its effect on the beam-column interaction formulae in equation 1 and 2.

From the left hand plot in Figure 16 it can be seen that buckling curve $b$ for flexural buckling is a decent fit to the resulting $0.1 \%$ quantile, but the lower and higher relative slenderness values, namely $\lambda_{z}<0.5$ and $\lambda_{z}>1$, the buckling curve is on the conservative side with a decent margin of up to about $13 \%$ for large relative slenderness ratios. Up to $\lambda_{z}=0.5$ the effects of strain hardening will increase its ultimate capacity, explaining the difference in this range. In the range of 0.5 to 1.0 the curve does seem to have a better fit to the $0.1 \%$ quantile of the test results, but here some values are slightly non-conservative which can also be seen in the right hand part of Figure 16. In this $\lambda$-range the effect of residual stress is significant and the idealized linear stress distribution might influence the results. Also as the member starts behaving more elastic, the geometrical imperfection will start influencing results in this range. For the hot rolled design case the curvature of the LTB buckling curve shown in Figure 17 seem to correlate well with the shape itself of the $0.1 \%$ quantile, although the Eurocode curve is at a higher value. This means that the LTB curves seem to be nonconservative throughout almost the whole range of slenderness values tested, with a peak in relative difference of $\sim 9 \%$ around $\lambda_{z}=1.0$ as seen in Figure 17 in the right hand plot.

The design equation used to calibrate the Eurocode lateral torsional buckling curves does not consider rotational geometrical imperfections $\phi$, see [2] and [28]. Figure 18 illustrates the correlation between ultimate capacity and the imperfection 

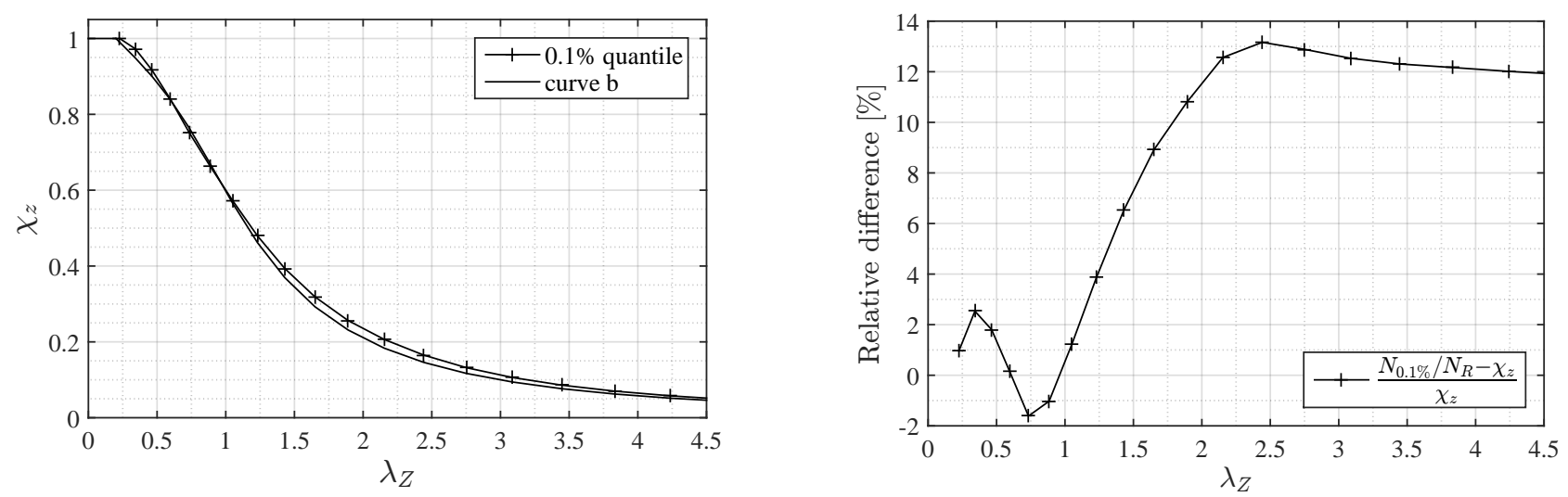

Figure 16: Weak axis flexural buckling curve compared to the $0.1 \%$ quantile.
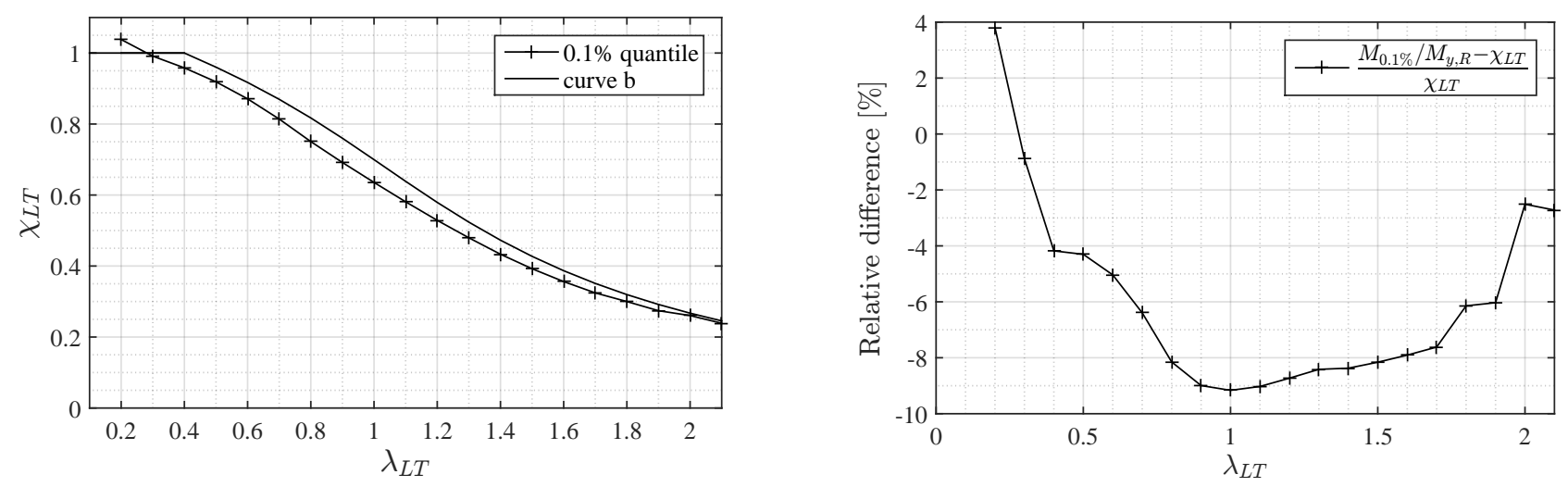

Figure 17: Lateral torsional buckling curve compared to the $0.1 \%$ quantile.

scale factor $\bar{e}$, given by a correlation coefficient $R(-1 \leq R \leq 1)$. A similar study was carried out in [29], where statistical dependence between the amplitude of the axis initial curvature and lateral-torsional buckling resistance was studied. These figures show that the pure bending case is highly dependent on the geometrical imperfection throughout the tested slenderness range, while the axial force case is only highly dependent in the intermediate range. The high correlation between ultimate capacity and geometrical imperfections in the pure bending case, suggest that a part of the error in the Eurocode design curves is due to the fact that rotational imperfections $\phi$ are neglected. It should be noted here that the small amount of input sets, i.e. 30 is not sufficient to make solid conclusions based on correlation, but it gives a pointer to the most influential parameter.

The cut-off value at 0.4 can be seen to be on the unsafe side compared to the $0.1 \%$ quantile, which goes above 1.0 at a lateral torsional slenderness value in the area of 0.3 . This suggest that the choice of using 0.4 as a cut-off value to comply with older codes [2], is non-conservative. The ECCS Technical Committee 8 [30] came to the opposite conclusion using a reliability analysis. All in all the pure flexural buckling curve $b$ of the Eurocode does seem to give a decent fit well on the safe side, while the pure lateral torsional buckling curve for the hot rolled section does not. These results are similar to previous works of Taras and Greiner, [19], and working group documents from ECCS, [27]. The results also coincides with those found in the preliminary testing of the finite element model using nominal input parameters, see [9].

\subsection{Interactional buckling for compression and bending}

In this section the beam-column interaction equations (1) and (2) with interaction factors from Method 1 and Method 2, are compared to the $0.1 \%$ quantile of the GMNIA simulation. In the following the results are grouped according to their slenderness value. First the low slenderness range of $\lambda_{L T}=0.2$ to 0.9 and the higher range of $\lambda_{L T}=1.0$ to 2.1 . This provides a decent illustration of how the accuracy of the methods develops through the whole range of slenderness values investigated.

For the low slenderness range Figure 19 shows the $0.1 \%$ quantile results. For the lateral torsional slenderness of 0.2 the beam-column is very stocky and it can be discussed whether or not the member can be considered to be a beam-column for this case. To properly comprehend the development of the capacity as the slenderness increases it is described in detail in the following. It can be seen in this plot for $\lambda_{L T}=0.2-0.5$ that the $0.1 \%$ quantile interaction curve has a rather parabolic shape when the member is loaded heavily in bending and the capacity ends up being larger than unity for pure bending. This parabolic shape can be explained by the relationship between the plastic moment capacity as a function of axial compression for double 

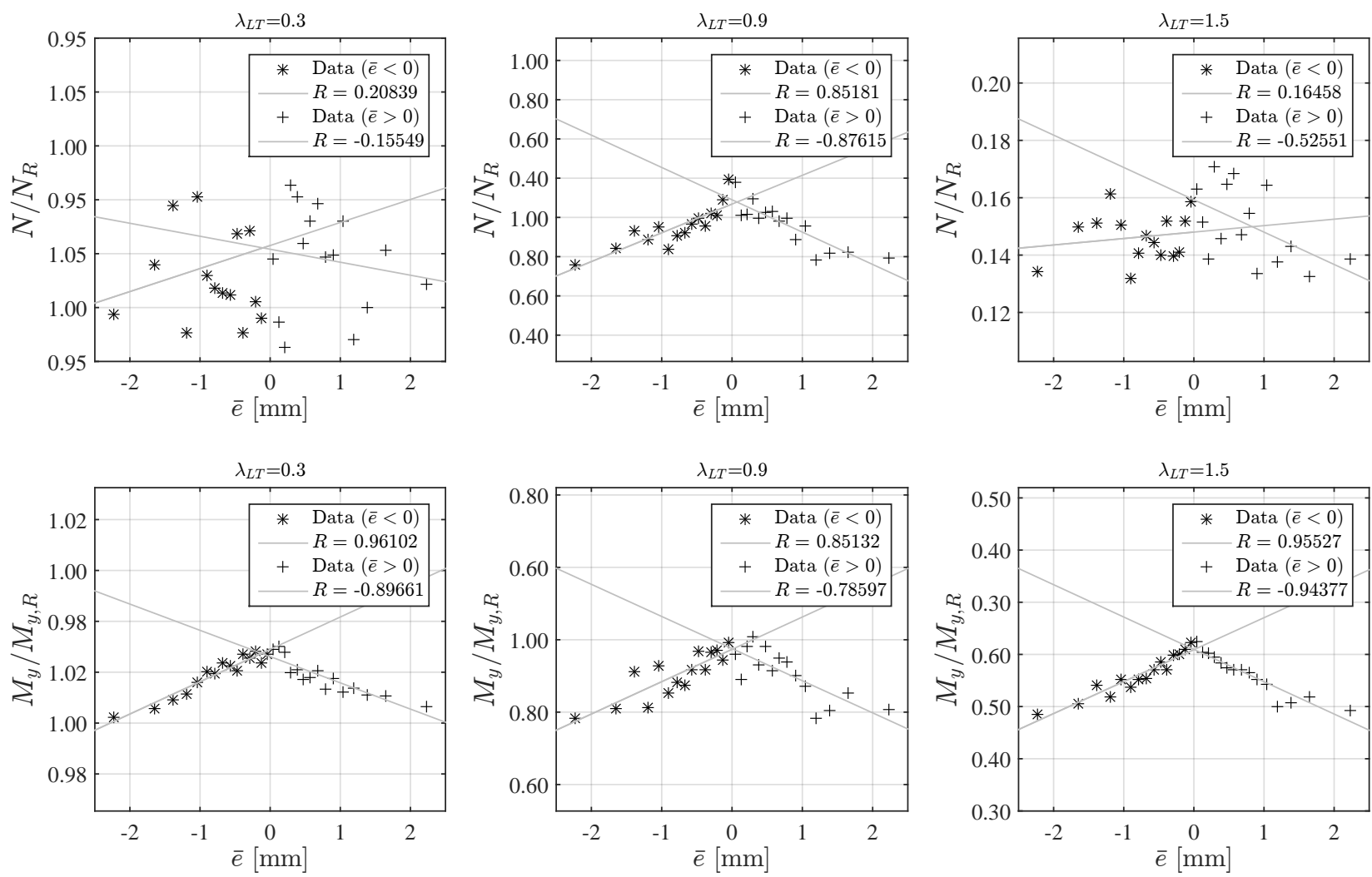

Figure 18: Trend lines with given correlation coefficients for the axial compression and pure bending resistance dependency on the normalized imperfection factor $\bar{e}$ split into eccentricities lower than or larger than zero.

symmetric profiles as given in [31] as

$$
\frac{M_{y}}{M_{y, R}}=1-\left(\frac{N}{N_{R}}\right)^{2} \frac{A^{2}}{4 t_{w} W_{y, p l}}
$$

As the slenderness values are low, the stress should have a plastic distribution. Here the squared expression concerning the axial force in (31) will give a shape similar to that observable in Figure 19 for $\lambda_{L T}=0.2-0.5$, and the linear additive form of the Eurocode formulae is not suited to properly describe the behaviour here as it does not contain a quadratic term. As the slenderness is increased to 0.4 the capacity curve has become quite linear and it can be observed that the fit with both Eurocode methods is quite good, although the overestimation of the lateral torsional buckling capacity can be seen. Ultimately it can be said that in the range of lower slenderness values, both Method 1 and Method 2 have a decent fit to the $0.1 \%$ quantile. Method 1 is slightly less conservative for the load cases with medium to high amounts of axial force, as it was able to follow the curvature of the $0.1 \%$ quantile to a larger extent than Method 2.

In the lower slenderness range from 0.4 to 0.7 Figure 19 the interaction curves of the Eurocode are closest to the $0.1 \%$ quantile especially for $\lambda_{L T}=0.6$. An interesting trend that can be observed is that the curvature characterized by the plastic stress diminishes as the member length increases, and the stress distribution in the flanges will to a lesser degree show plastic behaviour. Furthermore the quantile curve is starting to take on a more parabolic shape in the load cases where axial compression is dominating, while the curve takes on a more linear shape for the load cases which are dominated by bending moment as the slenderness increases. This is due to the fact that the member is starting to become so slender that the flexural buckling plays a more predominant role on the load carrying capacity, as the entire cross section is experiencing compression stress and the beam-column buckles about the weak axis before the bending moment starts to become a limiting factor. When comparing to the Eurocode formulae it becomes apparent that the Eurocode approximation of the capacity curve is not capable of fully emulating the properties of the $0.1 \%$ quantile as the slenderness increases. The Eurocode is increasingly on the "unsafe" side of the quantile curve when the member is loaded mainly in bending, this non-conservative trend seems to be larger in Method 2 which for the slenderness of 0.8 can be seen to be unsafe for half of the load cases. On the other hand it can be observed that both methods fail to follow the parabolic shape of the quantile plot and thus the load carrying capacity for the load cases with axial compression dominating is underestimated, a trend that seems to be increasing as the slenderness is increased.

Figure 20 shows the results for the higher range of lateral torsional slenderness, i.e. $\lambda_{L T}=1.0$ to $\lambda_{L T}=2.1$. For this range the inaccuracies of the design carrying capacity at the pure load cases are starting to make the apparent fit worse, nevertheless some noticeable trends can still be seen. It can be seen that in 

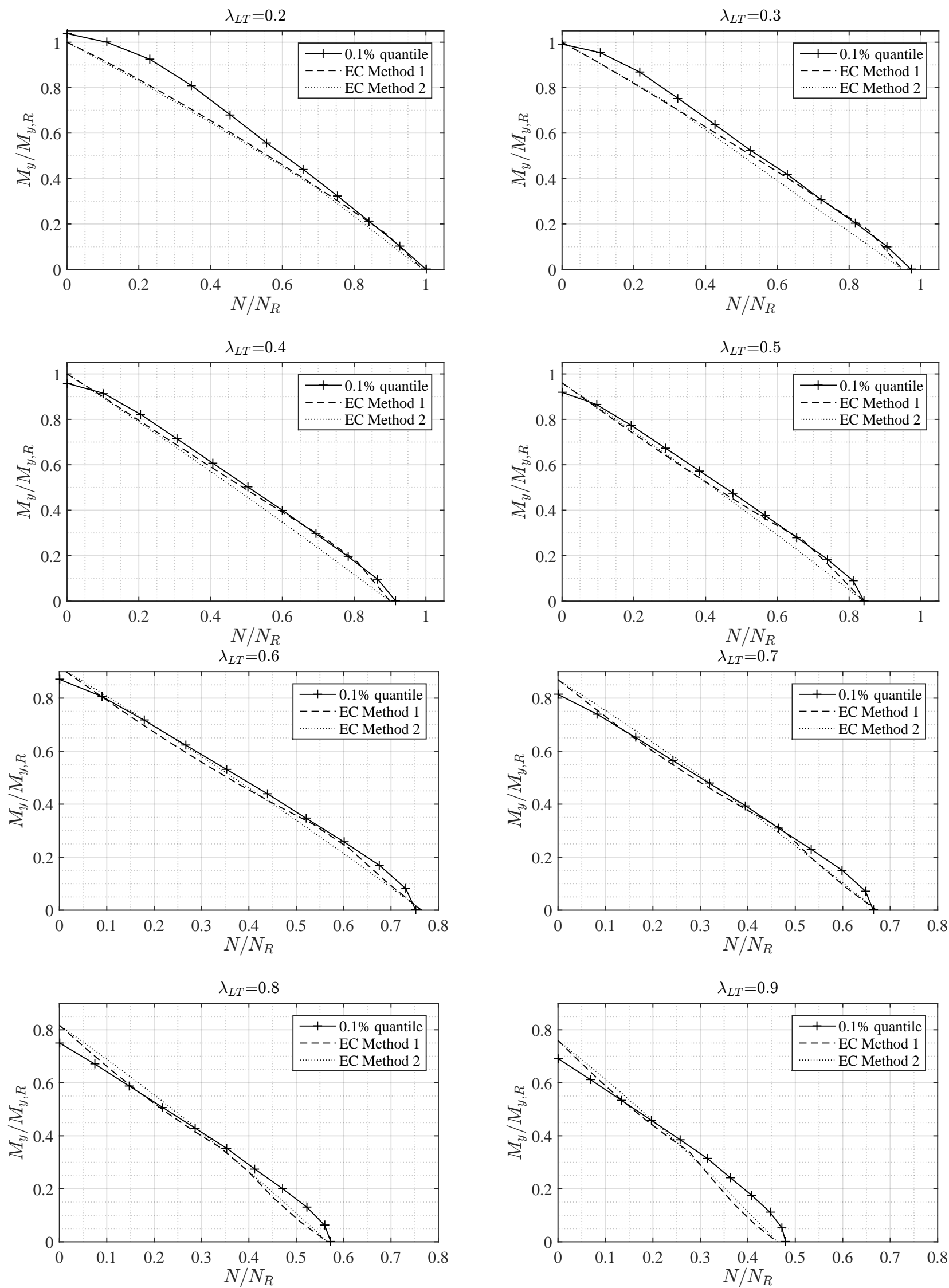

Figure 19: 0.1\% quantile simulation results and Eurocode results using Method 1 and 2 in the lower slenderness range. 

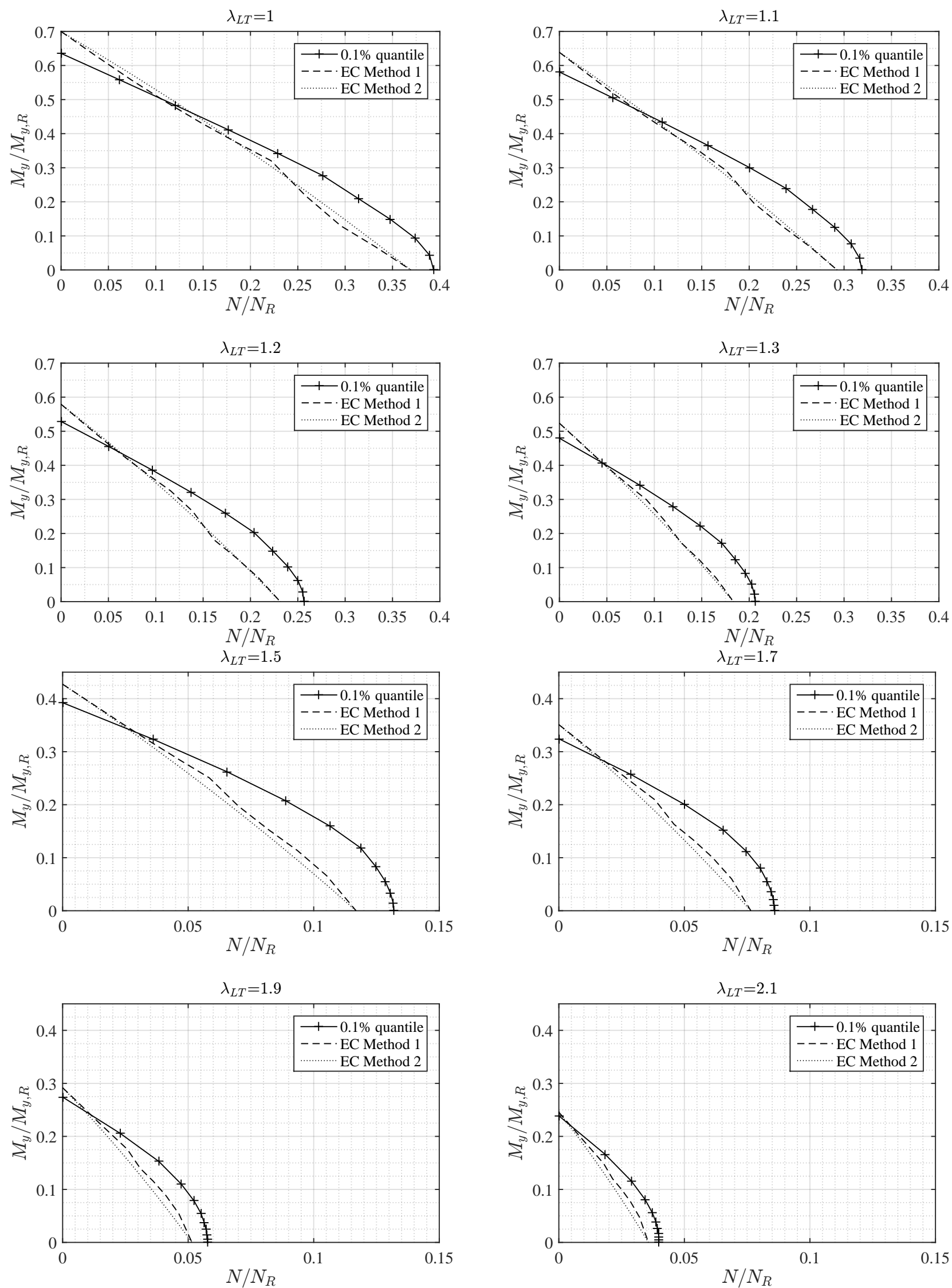

Figure 20: 0.1\% quantile simulation results and Eurocode results using Method 1 and 2 in the higher slenderness range. 
this slenderness range the characteristics of the quantile curve that were discussed in the previous paragraph is further developed, namely a linear shape in the moment dominated load cases and a parabolic shape in the compression dominated load cases. Meaning a small change in bending moment will hardly influence the axial capacity at high levels, but a reduction in axial force will increase the moment capacity significantly. It can also be observed that the Eurocode formulae are pretty close to each other for both methods. Method 1 fluctuates a bit since both of the Eurocode formulae are active in this method, and the transition point between equation 1 and 2 can be seen to shift closer to the pure moment load case. This transition point is recognizable by the outwards pointing 'hump' in the curve close to the middle. The fact that this shift between the two design formulae moves towards more bending moment heavy load cases, reflects the results from the simulations where it can be seen that the weak axis flexural buckling is increasingly becoming the governing factor for the bearing capacity. This does however hold little significance since equation (1) calculated using Method 1 still fails to approximate the parabolic shape of the quantile plot in this slenderness range and thus the difference from Method 2 is minimal. Although the overestimation of the pure LT buckling capacity is relatively stable on about $8.5 \%-9 \%$ as seen in Figure 17, it can be seen that the intersection point between the Eurocode formulae and the quantile of the results from the reliability analysis, i.e. the transition point where the Eurocode goes from being non conservative to conservative is moving closer to the case of pure bending as the slenderness increases. For the highest shown slenderness's the members become very long and as a consequence the weak axis flexural buckling becomes more important in the buckling behaviour, as seen by the even more prominent parabolic shape of the quantile curve.

\subsection{Beam-column interaction factors $k_{y y}$ and $k_{z y}$}

Looking at the weak axis and strong axis interaction factors $k_{y y}$ and $k_{z y}$ the results can be interpreted further. In order to compare the results from the reliability analysis, these results need to be in the same format as the interaction factors themselves. By rewriting the expressions from the Eurocode regarding beam-column interaction, expressions for the interaction factors $k_{y y}$ and $k_{z y}$ can be written as:

$$
\begin{aligned}
& k_{y y}=\left(1-\frac{N_{0.1 \%}}{\chi_{y} N_{R}}\right) \frac{\chi_{L T} N_{R}}{M_{y, 0.1 \%}} \\
& k_{z y}=\left(1-\frac{N_{0.1 \%}}{\chi_{z} N_{R}}\right) \frac{\chi_{L T} N_{R}}{M_{y, 0.1 \%}}
\end{aligned}
$$

Where $N_{0.1 \%}$ and $M_{y, 0.1 \%}$ are the adjoint maximal axial force and bending moment obtained for the given proportional load ratio. It should be noted that the accuracy of these formulas is affected by the accuracy of the lateral torsional and flexural buckling reduction factors $\chi_{L T}$ and $\chi$.

Figure 21 illustrates the development of the $k_{y y}$ factor from Method 1, Method 2, and recalculated from the $0.1 \%$ quantile, as the amount of axial force is increased in the load cases. Regarding Method 1, it can be seen that it does an overall good job of approximating the development of the strong axis influence on the $M_{y}$ capacity, as the axial load increases for the range of tested slenderness values. Only having non-conservative results for the pure bending case, and for large axial forces. For pure bending this is caused by the inaccurate LTB curves, while the non-conservative values at high axial forces are irrelevant as the weak axis factor $k_{z y}$ is utilized in the interaction formulae at these load combinations. Method 2 on the other hand does a poor job of approximating the development of the curve as the slenderness of the member is increased, predicting far less influence on $M_{y}$ capacity from the strong axis. For the tested cross section profile Method 2 will only utilize the strong axis design equation (1) at a few load cases at lower slenderness values. This means that the inaccurate development of $k_{y y}$ is effectively irrelevant for $\lambda>0.3$.

For the weak axis interaction factor $k_{z y}$ in figure 22 it can be seen that for lower slenderness values the $k_{z y}$ values of Method 1 have an opposite slope compared to $k_{z y, 0.1 \%}$ as the axial force is increased in the intermediate slenderness range. When the $\lambda_{L T}$ is further increased a 'dip' in the curve appears caused by a lower bound of the plasticity interaction factor $C_{z y}$, a factor included in Method 1 to decrease the benefit from plastic interaction as flexural buckling becomes more critical at higher axial forces, see [32]. For the tested IPE 160 profile it can be seen that this 'dip' is somewhat delayed compared to the slope of the $0.1 \%$ quantile. A change in the cut off level of the plasticity interaction factor could possibly improve the fit of $k_{z y}$ for Method 1 compared to the $0.1 \%$ quantile curve, and additionally lead to less conservative results for higher slenderness values using the interaction equations (1) and (2). Method 2 with its linear approach leads to an overestimation of the influence of weak axis forces on $M_{y}$ in most load cases. Here the weak axis interaction formula (2) is governing for most of the load cases used in this simulation, as no intermediate restraints against weak axis buckling is present. 

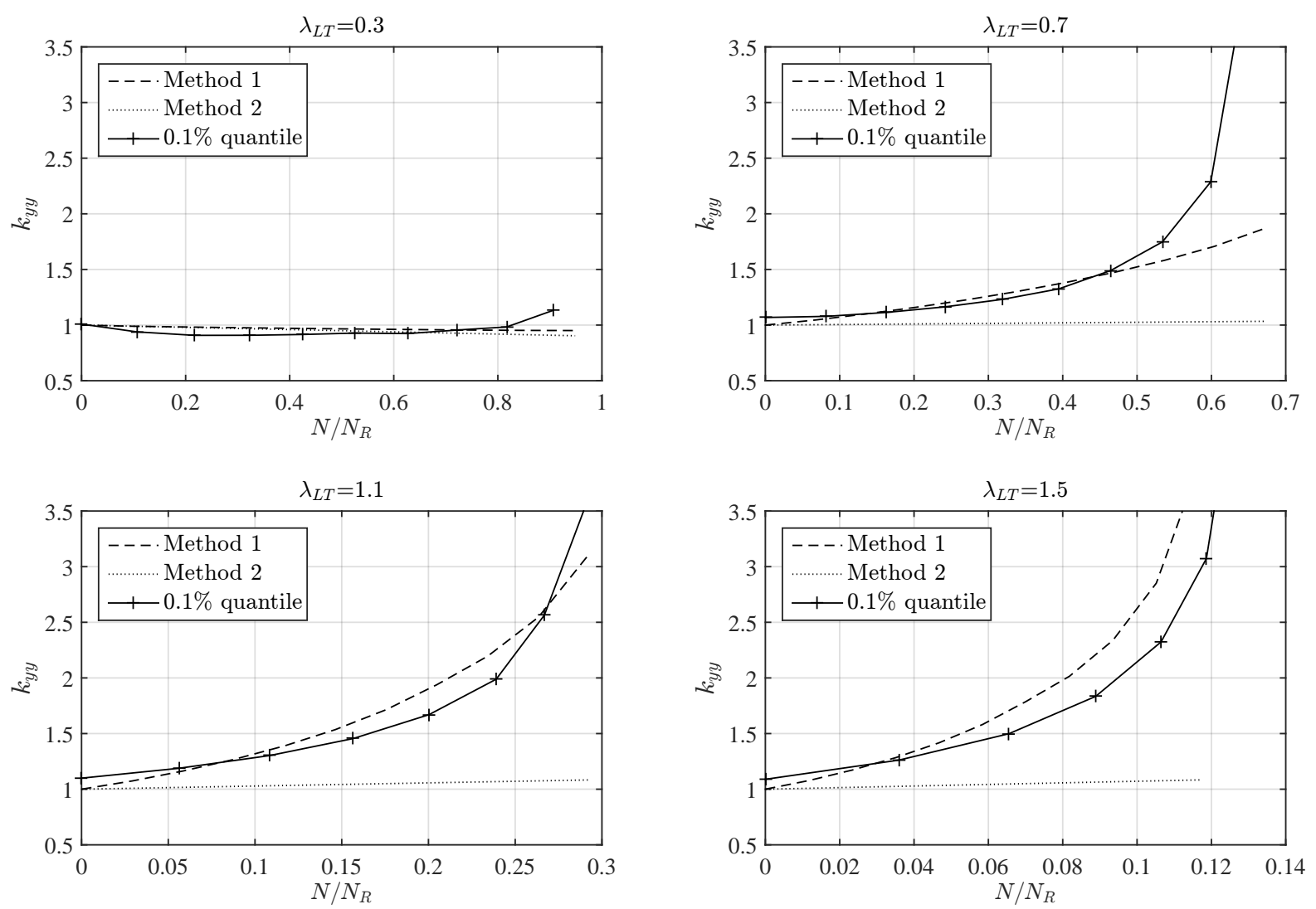

Figure 21: The development of the strong axis interaction factor $k_{y y}$, calculated from the $0.1 \%$ quantile and the two Eurocode methods
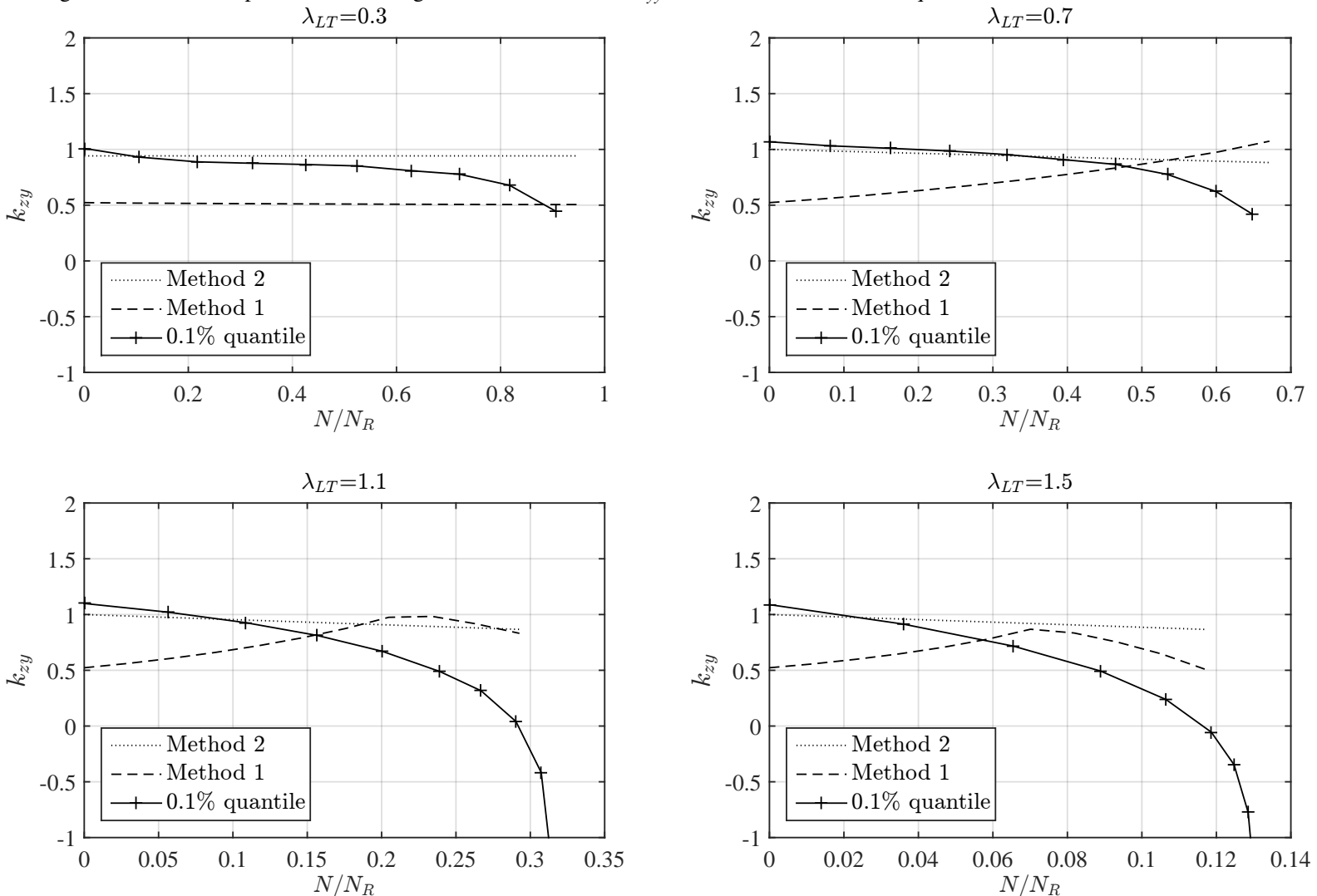

Figure 22: The development of the weak axis interaction factor $k_{z y}$, calculated from the $0.1 \%$ quantile and the two Eurocode methods 


\section{Conclusion}

The accuracy of the buckling interaction formulae according to the safety requirements and the probabilistic assumptions of Eurocode itself have been investigated. With the assumptions of this paper the probabilistic investigations performed show that the Eurocode prescribes an unsafe design when a beam-column member is loaded predominately in bending for members with a lateral torsional slenderness, $\lambda_{L T}$, larger than 0.4 . On the other hand it also shows that the design according to the Eurocode seems to become quite conservative for members loaded predominately in compression for beam-columns having a lateral torsional slenderness, $\lambda_{L T}$, larger than 0.8 .

In the case of pure axial force the Eurocode weak axis flexural buckling reduction factor $\chi_{z}$ provided conservative results compared to the $0.1 \%$ quantile of the results from the reliability analysis for nearly all slenderness values tested. Slightly nonconservative values were present in the range $0.5 \leq \lambda_{z} \leq 1.0$. This might be caused by both geometrical imperfections and residual stress being influential in this range, as seen from correlation between the input data and resulting capacity, whilst the beneficial effect from the strain hardening shown at lower slenderness values are decreased. For pure bending the Eurocode design values were non-conservative throughout the range of slenderness values, where the $0.1 \%$ quantile only started approaching the design curve for LT buckling for very high slenderness values $\left(\lambda_{L T}>2.0\right)$. Due to the limited amount of datasets included, it was hard to determine a sole cause of the poor fit. But geometrical imperfections did seem to have a large influence for all slenderness values, suggesting that omitting the initial rotation $\phi$ in the calibration of the lateral torsional buckling curves might contribute towards the poor fit. Concerning the beam-column interaction, it could be seen that factors from both Method 1 and Method 2 did a decent job of approximating the results for lower slenderness values. For higher slenderness values however, the fit of the curves deteriorated and it became apparent that the Eurocode formulae did not properly emulate the complex behaviour of the very slender beam-column. The strong axis interaction factor $k_{y y}$ does a good job of approximating the recalculated $k_{y y, 0.1 \%}$ values. Only showing signs of being non-conservative or overly conservative where the inaccurate $\chi$ factors from the Eurocode had a large effect, i.e. close to the pure load cases. The weak axis interaction factor $k_{z y}$ did not perfectly follow the recalculated $k_{z y, 0.1 \%}$ as the axial force was increased.

\section{Acknowledgement}

The work of the authors from Czech Republic has been supported and prepared within the project GAČR no. 17-01589S.

\section{References}

\section{References}

[1] J. Jönsson, T.C. Stan, European column buckling curves and finite element modelling including high strength steels, Journal of Constructional Steel Research, 128, 136-151, 2017,
[2] N. Boissonande,R. Greiner, J.R. Jaspart,J. Lindner, Rules for Member Stability in EN 1993-1-1. Background documentation and design guidelines, European Convention for Constructional Steelwork, ECCS-Publication No.119, 2006

[3] EN 1993-1-1:2005, Eurocode 3: Design of steel structures - Part 1.1: General rules and rules for buildings, CEN - European committee for Standardization, Brussels (Belgium), 2005.

[4] B. Snijder, Physical background to beam-column formulae in EC3, Report ECCS TC8, Report no. 2006-08, April 2006.

[5] EN 1990:2002 Eurocode O - Basis of structural design, CEN - European committee for Standardization, Brussels (Belgium), 2002.

[6] Z. Kala, Reliability analysis of the lateral torsional buckling resistance and the ultimate limit state of steel beams with random imperfections, Journal of Civil Engineering and Management, 21(7), 902-911, 2015,

[7] J. Strating, H. Vos, Computer simulation of the ECCS buckling curve using a Monte-Carlo Method. HERON, vol. 19, No. 2, 1973.

[8] ABAQUS CAE, v6.13-4, Simulia, 2014

[9] C. Gamst, M.S. Müller, Interaction of flexural and lateral torsional buckling in beam-columns, MSc Thesis, DTU Civil Engineering, Technical University of Denmark (DTU), June 2016.

[10] M.H. Faber, Statistics and Probability Theory: In pursuit of Engineering Decision Support, (Topics in Safety, Risk, Reliability and Quality, Vol. 18), Springer Publishing Company, 206 p., 2012.

[11] Y.G. Zhao, T. Ono, A general procedure for first/second-order reliability method (FORM/SORM). Structural Safety, 21, pp. 95-112, 1999.

[12] A.M.D. Mckay, R.J. Beckman, W.J. Conover, A Comparison of three methods for selecting values of input variables in the analysis of output from a computer code. Technometrics, 21(2), pp.239-245, 1979.

[13] DNV. (2013). Determination of structural capacity by non-linear FE analysis methods. Det Norske Veritas AS, Report DNV-RP-C208, June 2013

[14] EN 1993-1-5:2006. Eurocode 3: Design of steel structures - Part 1-5: Plated structural elements., CEN - European committee for Standardization, Brussels (Belgium), 2006.

[15] N. Boissonnade N, H. Somja, Influence of imperfections in FEM Modeling of Lateral Torsional Buckling, Proceedings of the Annual Stability confenence, SSRC - Structural Stability Research Council, Grapevine, Texas, April 18-21, 2012.

[16] EN 1090-2:2008 Execution of steel structures and aluminium structures - Part 2: Technical requirements for steel structures, CEN - European committee for Standardization, Brussels (Belgium), 2008.

[17] R. Maquoi,, J. Rondal, Mise en equation des nouvelles courbes Européennes de flambement, Construction Métallique, No. 1, 1978.

[18] ECCS 1984, Ultimate Limit State Calculation of Sway Frames with Rigid Joints, ECCS Technical Committee 8 - Structural Stability: Technical Working Group 8.2 - System, European Convention for Constructional Steelwork, ECCS-Publication No.33, 1984.

[19] A. Taras, R. Greiner, New design curves for lateral-torsional bucklingProposal based on a consistent derivation. Journal of Constructional Steel Research, 66(5), 648-663, 2010.

[20] J. Melcher, Z. Kala, M. Holický, M. Fajkus, L. Rozlívka, Design characteristics of structural steels based on statistical analysis of metallurgical products. Journal of Constructional Steel Research, 60(3-5), 795-808, 2004.

[21] J. Szalai, F. Papp, On the probabilistic evaluation of the stability resistance of steel columns and beams. Journal of Constructional Steel Research, 65, $569-577,2009$

[22] A. Sadowski, J.M. Rotter, T. Reinke, T. Ummenhofer, Statistical analysis of the material properties of selected structural carbon steels. Structural Safety, 53, 26-35, 2015.

[23] Z. Kala, Sensitivity and reliability analysis of lateral-torsional buckling resistance of steel beams. Archives of Civil and Mechanical Engineering, 15, 1098-1107, 2015.

[24] Z. Kala, J. Melcher, L. Puklickỳ, Material and geometrical characteristics of structural steels based on statistical analysis of metallurgical product, Journal of civil engineering and management, 15(3), 299-307, 2009.

[25] T.W. Anderson, D.A. Darling, Asymptotic theory of certain "goodnessof-fit" criteria based on stochastic processes, Annals of Mathematical Statistics, 23, 193-212, 1952.

[26] T.W. Anderson, D.A. Darling, A Test of Goodness-of-Fit, Journal of the American Statistical Association, 49, 765-769, 1954.

[27] ECCS TC 8 ad-hoc-WG, Interaction formulae for EC 3, Report 20 pp. 
1-15 \& 1-14, March, 2000.

[28] Kaim P. Spatial buckling behaviour of steel members under bending and compression, PhD Thesis, Graz University of Technology, Austria, 2004

[29] Z. Kala, Elastic lateral-torsional buckling of simply supported hot-rolled steel I-beams with random imperfections, Procedia Engineering, 57, 504514, 2014.

[30] C. King, Design moment of resistance Lamda_bar_LT0.4, ECCS Report No. TC8-2001-18, 2001, (Also on CD accompanying [2]).

[31] I.M.J. Rombouts, H.H. Snijder, R.W.A. Dekker, P.A Teeuwen, Resistance to moment-normal force interaction of I-shaped steel sections. Journal of Constructional Steel Research, 127, 28-40, 2016

[32] N. Boissonnade, J.P. Jaspart, J.P. Muzeau, M. Villette, Improvement of the interaction formulae for beam columns in Eurocode 3. Computers and Structures, 80(27-30), 2375-2385, 2002 